\title{
Electrical Breakdown Properties of Clay-Based LDPE Blends and Nanocomposites
}

\author{
Mostafa Eesaee $\mathbb{D}^{D},{ }^{1}$ Eric David $\left(\mathbb{D},{ }^{1}\right.$ Nicole R. Demarquette, ${ }^{1}$ and Davide Fabiani ${ }^{2}$ \\ ${ }^{1}$ Mechanical Engineering Department, École de Technologie Supérieure, Montréal, QC, Canada \\ ${ }^{2}$ Department of Electrical, Electronic, and Information Engineering, University of Bologna, Bologna, Italy \\ Correspondence should be addressed to Mostafa Eesaee; m.eesaee@yahoo.com
}

Received 5 September 2017; Revised 20 November 2017; Accepted 27 November 2017; Published 11 January 2018

Academic Editor: Alessandro Pegoretti

Copyright @ 2018 Mostafa Eesaee et al. This is an open access article distributed under the Creative Commons Attribution License, which permits unrestricted use, distribution, and reproduction in any medium, provided the original work is properly cited.

\begin{abstract}
Microstructure and electrical breakdown properties of blends and nanocomposites based on low-density polyethylene (LDPE) have been discussed. A series of LDPE nanocomposites containing different amount of organomodified montmorillonite (clay) with and without compatibilizer have been prepared by means of melt compounding. Two sets of blends of LDPE with two grades of StyreneEthylene-Butylene-Styrene block copolymers have been prepared to form cocontinuous structure and host the nanoreinforcement. A high degree of dispersion of oriented clay was observed through X-ray diffraction, scanning, and transmission electron microscopy. This was confirmed by the solid-like behavior of storage modulus in low frequencies in rheological measurement results. An alteration in the morphology of blends was witnessed upon addition of clay where the transportation phenomenon to the copolymer phase resulted in a downsizing on the domain size of the constituents of the immiscible blends. The AC breakdown strength of nanocomposites significantly increased when clay was incorporated. The partially exfoliated and intercalated clay platelets are believed to distribute the electric stress and prolong the breakdown time by creating a tortuous path for charge carriers. However, the incorporation of clay has been shown to diminish the DC breakdown strength of nanocomposites, mostly due to the thermal instability brought by clay.
\end{abstract}

\section{Introduction}

It has been more than eight decades that synthetic polymers have been used as solid electrical insulating materials because of their excellent dielectric properties, the most important of which is the high dielectric breakdown strength. When a dielectric is subjected to a rising voltage, with a high enough applied electrical field the electrical pressure will eventually overcome the insulating material and electrical charge carriers will flow. Current flow behavior through an insulator is not linear as in conductors and practically no electrons will flow below a certain threshold level, above which current will gain sufficient kinetic energy and forcibly runs through the material. Electrons will multiply as a result of the ionization of the collision process, electronic conduction takes place, and breakdown occurs. This mechanism is known as avalanche process $[1,2]$ and the dielectric strength is defined as the highest voltage the insulator withstands before breakdown divided by its thickness. However, this is not the only known mechanism and breakdown may occur in advance of electron avalanche by insulation melting due to temperature rise (thermal breakdown) and enhanced electric stress when the insulation thickness is mechanically reduced (electromechanical breakdown) or due to partial discharge [3-6]. In reality the mechanism of dielectric breakdown is more complicated in many polymers and preexisting discontinuities also contribute to the cumulative breakdown. It was found out that impurities, defects, and degradation caused by electric field or heat will accelerate the failure [7]. Extensive works have been done to understand the behavior of polymers towards electrical breakdown which has led to considering several factors such as thickness, surrounding medium, pressure, and temperature, all along with the complicated morphology and structure of polymers which make the understanding of breakdown process very difficult.

One proposed solution to improve the breakdown strength of polymers consists of adding a reinforcing 
inclusion as fillers (composites). Despite improvements in mechanical and thermal properties, micro inclusions are believed to decrease the breakdown strength of polymers as they may act as defects [8]. Consequently, nanofiller inclusions have been introduced recently to overcome the negative effects $[3,9]$, thus creating a new area of materials called nanometric dielectrics or nanodielectrics [10]. Nanoparticles which may be chemically modified with different approaches in order to have polar or nonpolar functional groups on their surface have shown very promising results [11]. It is well known that they have a great influence on breakdown properties of polymers, especially by the change in morphology of the semicrystalline polymers [12]. They reduce the internal field [13] and alter the space charge distribution within the polymer matrix [14]. Furthermore, the interface between polymer and nanoparticle plays a crucial role in the dielectric breakdown performance $[15,16]$. The final obtained morphology and the physical and chemical characteristics of the interface are greatly influenced by the dispersion and localization of nanoparticles and the nature of both phases, which will eventually influence the breakdown process by changing the microscale aspects, that is, traps, free volume, and carrier mobility [17]. Therefore, considerable attentions must be paid to tailor the interface with proper physical and chemical methods to obtain improved dielectric breakdown properties $[18,19]$.

Another well-established approach to develop new materials is polymer blending [20]. Since usually polymers have low mixing entropy, most polymer pairs tend to make an immiscible blend [21]. During the mixing process and at rest, the dynamic interplay between rheological phenomena determines the final morphology of the blend. When having different mixing proportion, the minor component tends to distribute all over the major phase as droplets. However, in a narrow range of composition with proper processing, the blend microstructure can turn into cocontinuous, distinguished by a mutual interpenetration of the two components. This type of microstructure is well-known for its tunable and substantial combination of functional and structural properties but is hard to achieve [22]. It has been well-established that nanoparticles can be adopted to stabilize the morphology of immiscible blends [23-25]. However, this approach has not been fully employed to discover the potential improvements in electrical breakdown properties of polymers.

In this paper, attempts to evaluate the short-term AC and DC electrical breakdown properties for clay-based nanocomposites of low-density polyethylene (LDPE) have been presented, alongside with observation of the morphology of those materials. Also the possibility of using a binary blend to achieve a tailored dispersion of nanoclays to result in an improved AC and DC electrical breakdown was evaluated.

\section{Experimental}

2.1. Materials and Processing. Commercially available premixed LDPE/clay masterbatch (nanoMax ${ }^{\circledR}$-LDPE) containing 50\% organomodified montmorillonite (O-MMT) was supplied from Nanocor and used as the source of the nanoreinforcement. The masterbatch was further diluted with low-density polyethylene (LDPE), supplied from Marplex in powder form with a density of $0.922 \mathrm{~g} / \mathrm{cm}^{3}$ and MFI of $0.9 \mathrm{~g} / 10 \mathrm{~min}\left(190^{\circ} \mathrm{C} / 2.16 \mathrm{~kg}\right)$, to the desired concentrations of clay. Maleic anhydride grafted linear low-density polyethylene (LLDPE-g-MA) was supplied from DuPont (Fusabond M603) and has been used as a compatibilizer. It has a density of $0.940 \mathrm{~g} / \mathrm{cm}^{3}$ and MFI of $25 \mathrm{~g} / \mathrm{min}$ and is being referred to as MA in this manuscript. Two series of nanocomposites were prepared with and without $5 \mathrm{wt} \%$ of the compatibilizer, with concentration profile of clay being set as 1, 2.5, 5, 10, and 15\%.

The same procedure was used to prepare blends and nanocomposites of LDPE with two grades of polystyreneb-poly(ethylene-co-butylene)-b-polystyrene (SEBS) thermoplastic elastomer supplied from Kraton: G1652 and FG1901. The former with a MFI of $5\left(230^{\circ} \mathrm{C} / 2.16 \mathrm{~kg}\right)$ based on ASTM D1238 (as declared by the supplier) is referred to as SEBS in this manuscript. The latter with a MFI of 22 which contains $1.4-2 \mathrm{wt} \%$ of maleic anhydride (MA) is referred to as SEBSMA. Both grades contain $30 \mathrm{wt} \%$ fractions of polystyrene (PS) block in their structure and have a density of $0.91 \mathrm{~g} / \mathrm{cm}^{3}$.

Melt compounding via extrusion process has been performed using a corotating twin-screw extruder. All materials were dried prior to extrusion in a vacuum oven at $45^{\circ} \mathrm{C}$ for at least $36 \mathrm{~h}$ and manually premixed. A temperature profile of $145-170^{\circ} \mathrm{C}$ was set from hopper to die. The pellets obtained were press-molded using an electrically heated hydraulic press into thin plates with various thicknesses regarding the future characterization. Samples were first preheated for 5 minutes and then hot-pressed at $155^{\circ} \mathrm{C}\left(165^{\circ} \mathrm{C}\right.$ for blends) for another 5 minutes under the pressure of $10 \mathrm{MPa}$. Press plates then were water-cooled with a rate of $10^{\circ} \mathrm{C}$ per minute to the ambient temperature. Table 1 represents a summary of the composition of the final blends and nanocomposites. In case of blends the mass fractions of the two phases are set equal. Note that the nominal percentages of clay have been used since the thermogravimetric analysis (TGA) showed (not shown here) that the actual weight percentage of clay in the masterbatch is $32 \mathrm{wt} \%$.

2.2. Characterization. The morphology of the as-obtained nanocomposites was characterized by high resolution scanning electron microscopy (SEM) using a Hitachi SU-8230 Field Emission-STEM microscope. Samples were cryogenically cut and sputtered with a $20 \mathrm{~nm}$ layer of platinum using a Turbo-Pumped Sputter Coater (Q150T S) prior to the observation. Solvent extraction has been used to investigate the microscopic structure of the blends. Some samples were held in Toluene for $24 \mathrm{~h}$ while being gently stirred at room temperature and then washed with alcohol before SEM observation.

Transmission Electron Microscopy has been also conducted. With respect to SEM, it employs electron beam instead of light beam. It has been done using a FEI Tecnai G2F20 S/TEM, operated at $200 \mathrm{kV}$. The device is equipped with a Gatan Ultrascan $40004 \mathrm{k} \times 4 \mathrm{k}$ CCD Camera System (Model 895). Samples were cryogenically cut to create thin layers that allow electron beam penetration. The point-topoint and line resolutions of the TEM are, respectively, $0.24 \mathrm{~nm}$ and $0.17 \mathrm{~nm}$. 
TABLE 1: Composition and nomenclature of LDPE/SEBS blends and nanocomposites.

\begin{tabular}{lccccc}
\hline & LDPE $(w t \%)$ & Clay $(\%)$ & MA (wt\%) & SEBS (wt\%) & SEBS-MA (wt\%) \\
\hline LDPE/nC & $(100-n)^{*}$ & $n$ & - & - & - \\
LDPE/MA/nC & $(95-n)$ & $n$ & 5 & 50 & - \\
LDPE/SEBS & 50 & - & - & - & - \\
LDPE/SEBS-MA & 50 & - & - & 47.5 & - \\
LDPE/SEBS/5C & 47.5 & 5 & - & - & 47.5 \\
LDPE/SEBS-MA/5C & 47.5 & 5 & & -
\end{tabular}

${ }^{*} n=1,2.5,5,10$, and 15 .

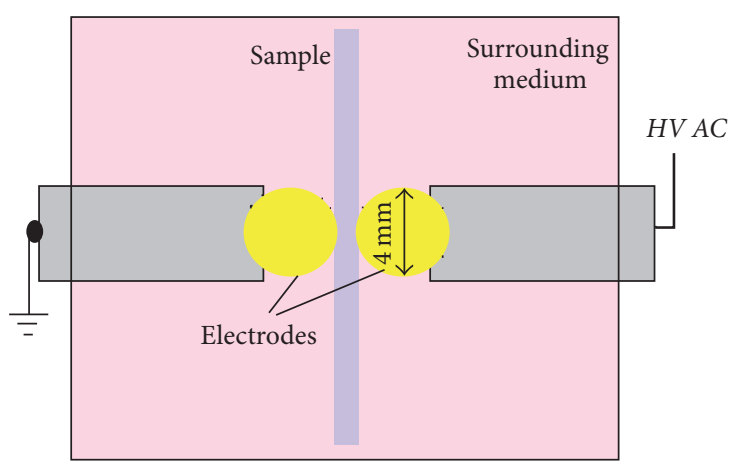

(a)

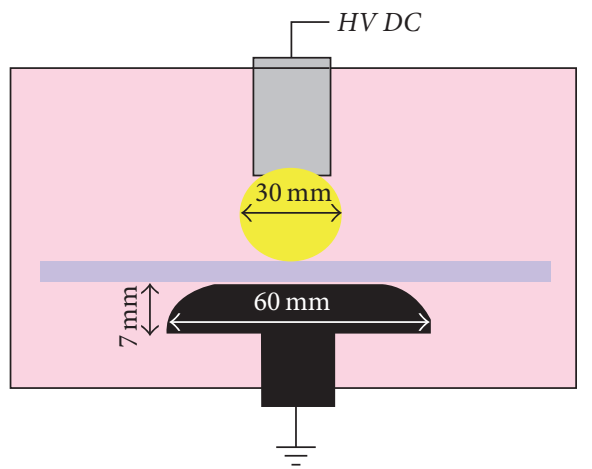

(b)

FIGURE 1: Electrical breakdown measurement setup for (a) AC short term and (b) DC short term.

$\mathrm{X}$-ray diffraction has been employed to evaluate the degree of dispersion and intercalation/exfoliation of the nanoclay using PANanalytical X'Pert Pro with $\mathrm{K} \alpha$ radiation $(\lambda=1.542 \AA)$. Accelerating voltage and electrical current was set to $40 \mathrm{kV}$ and $40 \mathrm{~mA}$, respectively. The scanning was conducted from $2^{\circ}$ to $10^{\circ}$ with a step size of $0.102^{\circ}$ and the counting time was $400 \mathrm{~ms}$ per step. Bragg's law was used to calculate the intercalate spacing $\left(d_{001}\right)$ as

$$
2 d \sin \theta=\lambda \text {, }
$$

where $\lambda$ is the wavelength of the X-ray radiation used, $d$ is the distant between the diffraction of lattice plans, and $\theta$ is the diffraction angle measured [26].

The morphological data were further enriched by conducting rheological measurement at $160^{\circ} \mathrm{C}$ via a straincontrolled rheometer (MCR 501 Anton Paar). First a strain sweep was carried out to determine the linear viscoelastic range; then small amplitude oscillatory shear (SAOS) tests were performed in the frequency range from 0.01 to $300 \mathrm{rad} \cdot \mathrm{s}^{-1}$. Samples in parallel plate geometry with diameter of $25 \mathrm{~mm}$ were used in a $1 \mathrm{~mm}$ sample gap.

The AC short-term breakdown test was conducted to measure the dielectric strength of the samples using a BAUR DTA 100 device where the samples are gently held between the electrodes (ball-type, $4 \mathrm{~mm}$ diameter) while all immersed in insulating oil (Luminol TR-i, Petro-Canada) to avoid flashover. Method A from ASTM D149 was chosen, according to which the ramp was set to $2 \mathrm{kV} / \mathrm{s}$ and continued until failure of the sample. The test was performed at ambient temperature and the insulating oil was dried in vacuum oven for a minimum of $48 \mathrm{~h}$. Twenty specimens were tested for each sample. Each time before changing the sample, the oil was removed and fully replaced, and the electrodes were cleaned. A thickness of $140 \mu \mathrm{m}$ was used for the breakdown test; while to find out the role of thickness on the breakdown strength variation, the test was also conducted for two other thicknesses $(200 \mu \mathrm{m}$ and $300 \mu \mathrm{m})$ for LDPE/clay nanocomposites. A power law relationship was used to correct the measurement data as a result of the nonuniformity in the thickness of specimens, as discussed in [27].

The same approach was used to measure the DC breakdown strength of the samples having $200 \mu \mathrm{m}$ thickness. Specimens were placed between a spherical electrode on top (30 $\mathrm{mm}$ diameter) and a disk-shape electrode on the bottom. The diameter of the lower electrode was 60 with a rounding radius of $7 \mathrm{~mm}$. Electrodes were placed in a container while immersed in mineral oil. The specimens were subjected to a voltage raise of $5 \mathrm{kV} / \mathrm{s}$. Eight specimens were tested for each sample, between which the oil was renewed completely. LabView software was used to computerize the measuring system. Figure 1 depicts a schematic representation of the measurement setups used for both high voltage AC and DC breakdown tests. A commercially available software was used to retrieve the data for both $\mathrm{AC}$ and DC breakdown strengths based on two-parameter Weibull distribution.

\section{Results and Discussion}

3.1. X-Ray Diffraction (XRD). Figure 2 shows the X-ray diffraction spectra for the LDPE clay nanocomposites. This 


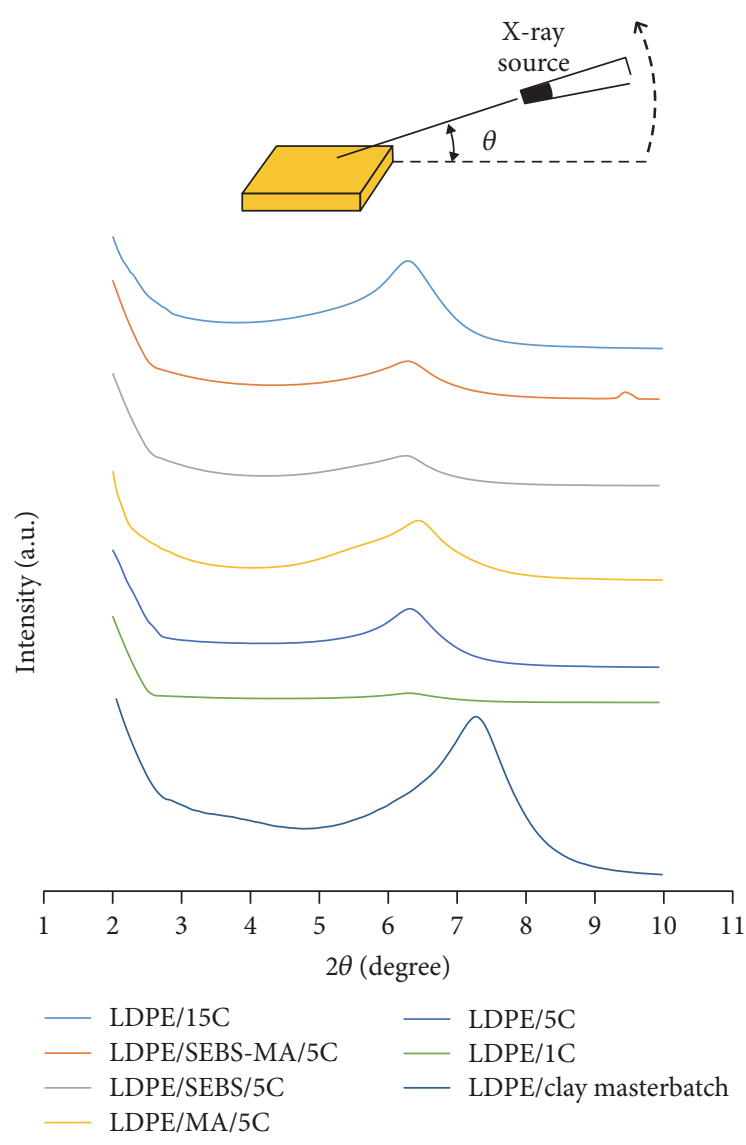

(a)
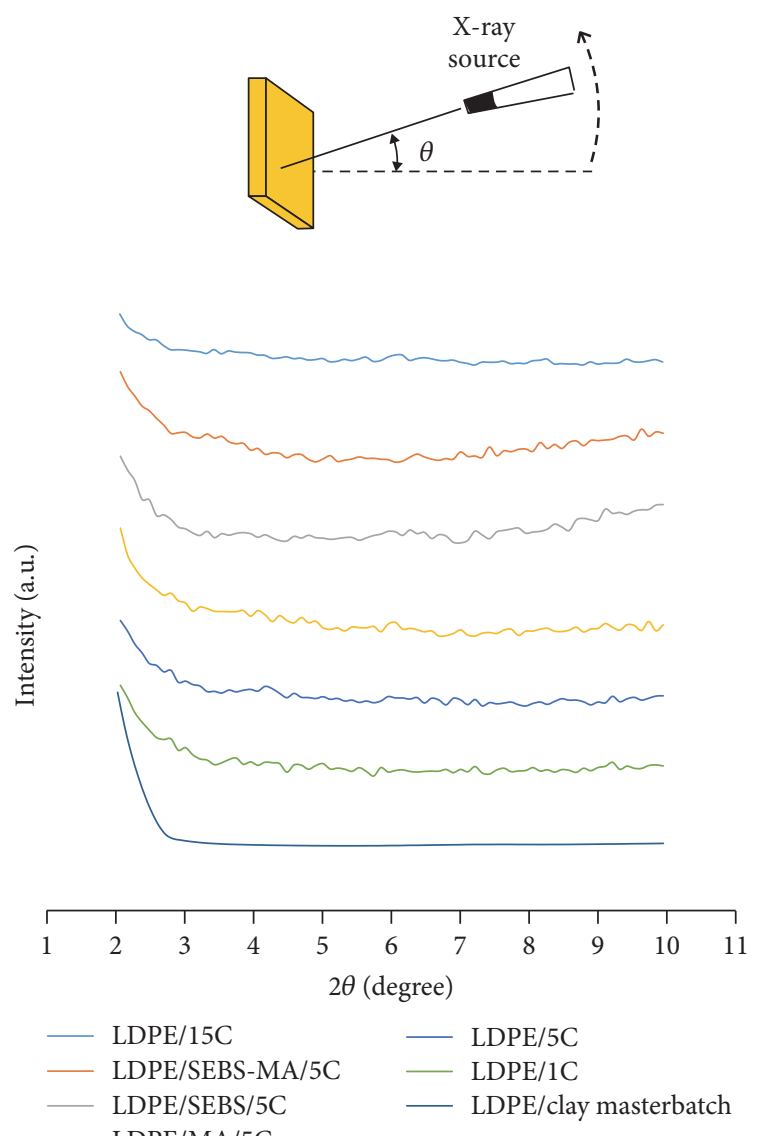

(b)

FIGURE 2: X-ray diffraction pattern for LDPE nanocomposites: (a) parallel emission and (b) perpendicular emission.

technique allows us to determine the interlayer distance of nanoclay by utilizing Brag's law. The identification of the nanocomposite structure can be done via monitoring the intensity, shape, and position of the basal reflection peaks. The layers of the silicates usually form stacks with a regular van der Waals gap, called the interlayer or the gallery. A single layer has a thickness around $1 \mathrm{~nm}$ but tactoids formed by several layers can reach up to several hundreds of micron when forming stacks [28]. According to Brag's law, a shift of diffraction peak towards lower diffraction angle is a sign of an increase in the interlayer spacing as a result of polymer intercalation. Higher extent of polymer intercalation would result in a greater shift towards lower value of $2 \theta$, signaling a better dispersion of the clay nanoplatelets $[28,29]$. This increase in interlayer spacing also decreases the periodicity which reflects a reduction in the intensity of the peak.

The XRD measurements were conducted in two different directions, having the radiation starting parallel and perpendicular to the surface of the sample. As can be seen in Figure 2(a), in parallel emission there is a peak at $2 \theta$ of 6.34 corresponding to an interlayer spacing of around $1.39 \mathrm{~nm}$ and no evident sign of the primary diffraction peak $\left(d_{001}\right)$, while the corresponding peak for masterbatch occurs at $2 \theta$ of 7.26 showing a shift of diffraction peak for nanocomposites to lower degrees originating from the increase in the interlayer spacing during the melt mixing. That means at least one extended polymer chain is intercalated between the stacks of silicate layers. As expected the intensity of the peak increases with the increase in the amount of clay incorporated. For sample containing $5 \mathrm{wt} \%$ of MA (LDPE/MA/5C), the diffraction peak occurs at the same place but is broader than the original nanocomposite (LDPE/5C). This broadening of the diffraction peak suggests that the degree of dispersion of the clay within the polymer matrix is further improved, possibly due to the polar interactions between the maleic anhydride groups in the compatibilizer and the hydroxyl groups of clay and the increase in the shear stress because of the low molecular weight of MA. This may end up in formation of covalent bond and facilitate the penetration of polymer chains into the galleries of clay [30].

When the direction of the radiation is normal to the surface of the sample (Figure 2(b)), nanocomposites patterns show some fluctuations but no clear peak can be recognized. The same pattern is seen for the masterbatch. This is probably due to the orientation of the clay layers parallel to the surface when molded in hydraulic press under high temperature and high pressure into thin plates. This was possible since the final thickness of the samples was all less than $300 \mu \mathrm{m}$, and under 


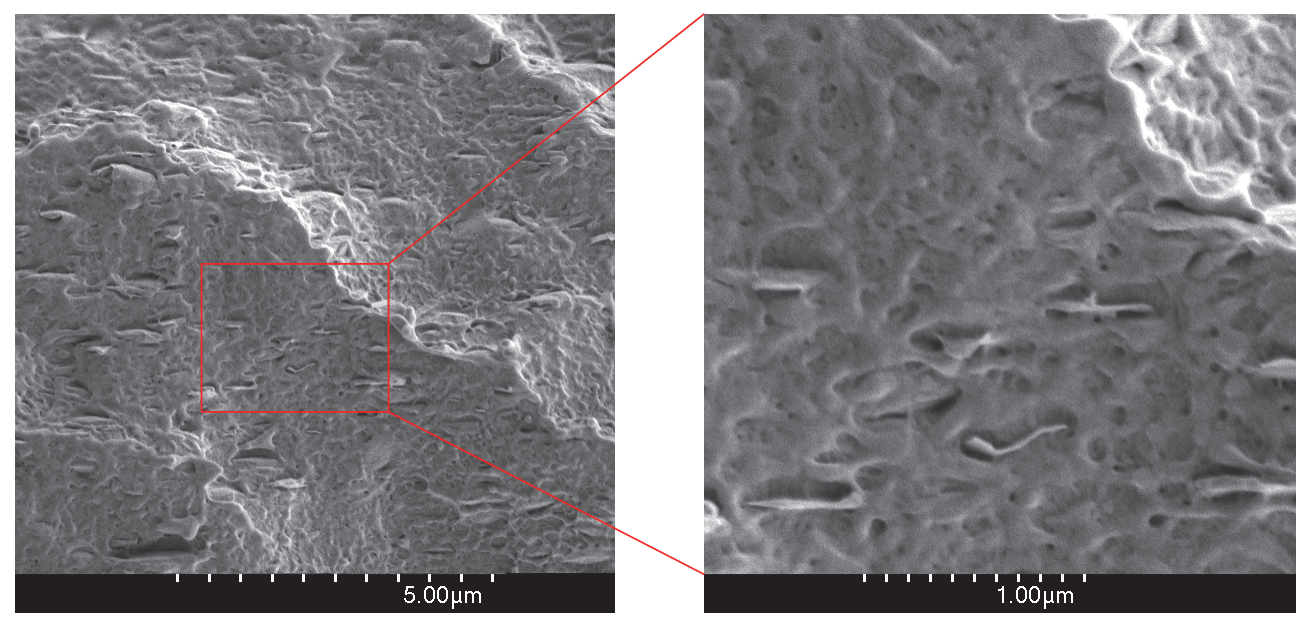

(a)

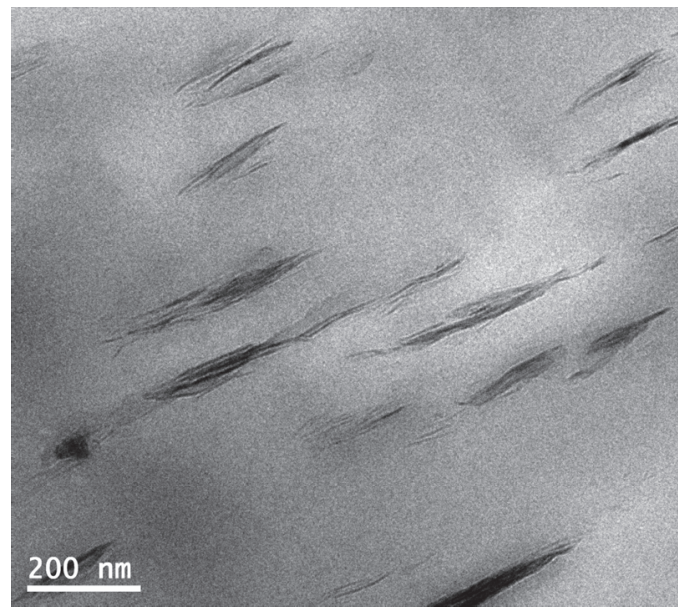

(b)

FIGURE 3: SEM (a) and TEM (b) micrographs for LDPE/5C.

pressure the molten polymer had to flow in the directions perpendicular to the applied pressure. Thicker samples have not been prepared; however, it is expected that the anisotropy of the clay is maximum under the highest applied pressure [31].

However, XRD do not fully reveal the spatial distribution of the layered silicates; besides, some layered silicates do not show observable basal reflections. Therefore, the morphology of the nanocomposite must also be evaluated by other means of spectroscopy.

\subsection{Scanning (SEM) and Transmission Electron Microscopy} (TEM). The dispersion of nanoclay was examined using SEM and TEM. Figure 3 shows both techniques' micrographs of LDPE nanocomposites reinforced with $5 \%$ clay. Stacks of clay tactoids with a high degree of aspect ratio and surface area are visible in both cases. They are uniformly distributed throughout the polyethylene matrix. A noticeable orientation of clay stacks is visible which is in agreement with the XRD results. The distances between clay sheets are huge and stacks are totally separated from each other. Moreover, there are clear signs of polymer intercalation in some clay stacks as can be seen in TEM micrograph. However, sheets of clay are not fully inlaid within the LDPE matrix and despite the achieved separation, a noticeable amount of gaps is visible from SEM micrograph in the interfacial area. This hints that even surface modification of the clay does not fully repair the poor bond and weak interaction between hydrophilic silicate layers with the hydrophobic polyethylene.

The SEM micrographs of blends and their nanocomposites are shown in Figure 4, alongside with their corresponding images where the SEBS phase is selectively removed using solvent extraction process. The white areas are believed to be the elastomer phase. When SEBS is blended with LDPE (a-d), a random micrometric mixture of the two phases is visible, which is revealed from the solvent extracted images to be a cocontinuous structure. When SEBS-MA is used (e-h), the resultant is still a cocontinuous structure. However, the elastomer phase is less evident, possibly because of the optical effects of MA grafted to the SEBS molecules.

Due to the complexity of the images, it is hard to point out the possible stacks of clay, but a noticeable change in 


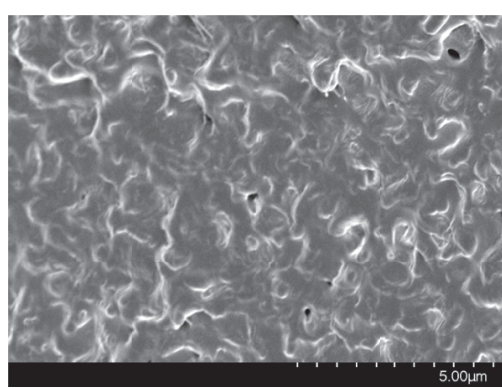

(a)

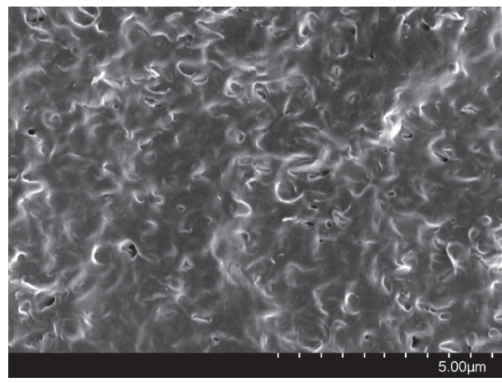

(c)

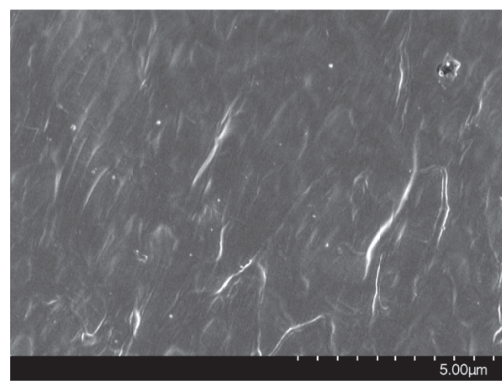

(e)

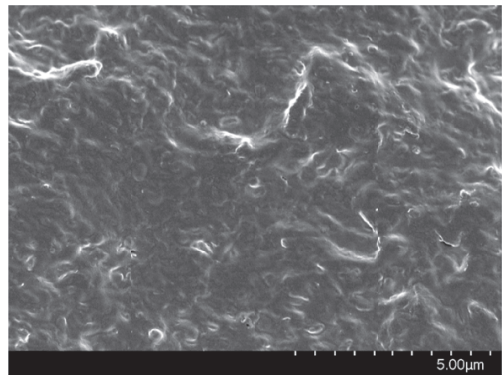

(g)
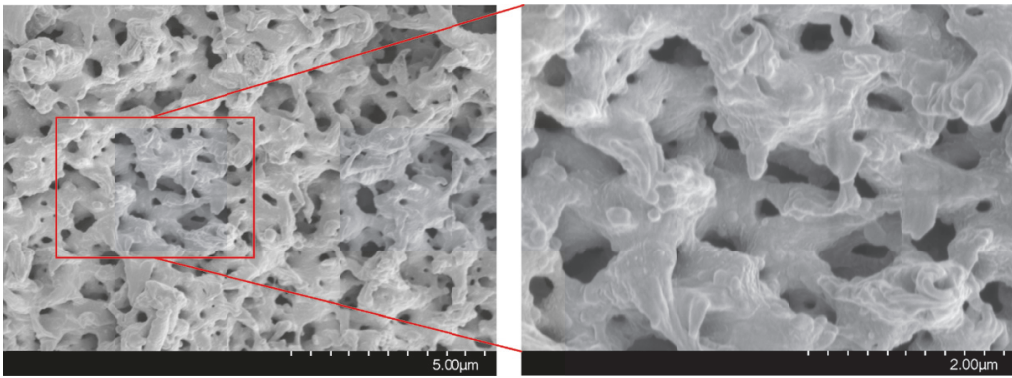

(b)
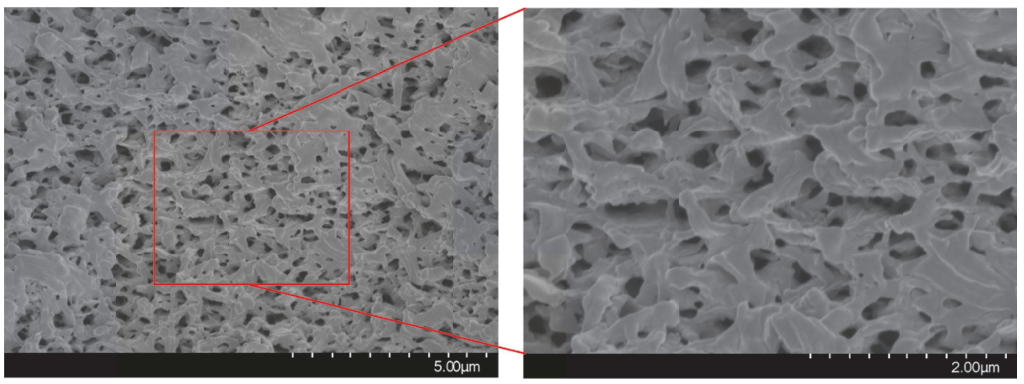

(d)
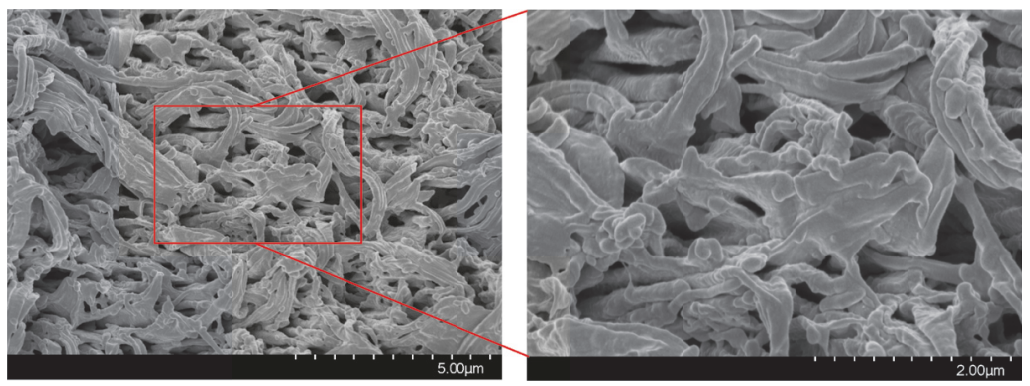

(f)
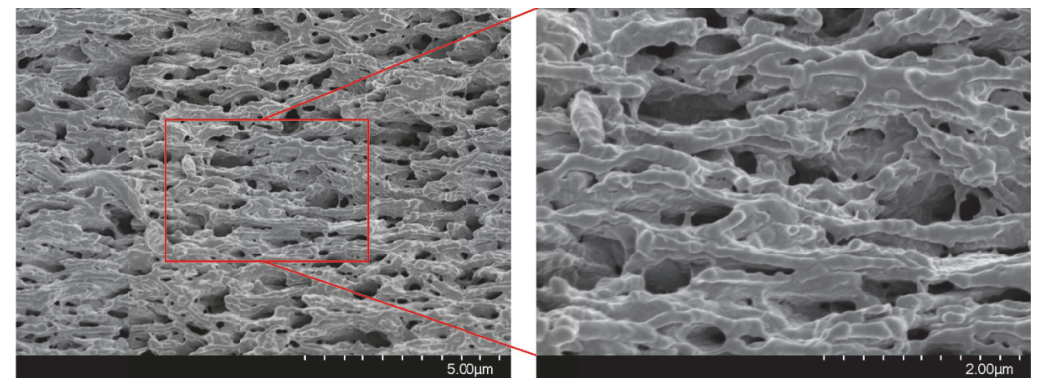

(h)

FIGURE 4: SEM micrographs of LDPE blends before and after solvent extraction: (a) and (b) LDPE/SEBS, (c) and (d) LDPE/SEBS//5C, (e) and (f) LDPE/SEBS-MA, and (g) and (h) LDPE/SEBS-MA/5C.

the structure of both blends is obvious when $5 \%$ of clay is incorporated. The nanocomposites maintain the cocontinuity but it goes to smaller dimensions. Regarding the elastomer phase, the curves and arcs are much smaller in the presence of nanoclay. Also the black holes in the solvent extracted images, representing the absence of the elastomer phase, have lower diameters. This downsizing effect of clay on the domain size of the constituents of the immiscible blends having cocontinuous structure has been previously reported [23, 32].
That means the introduction of clay into the blend actually alters the morphology of the blends. Clay may prevent or slowdown the coalescence phenomenon by acting as solid barriers or can act as compatibilizer and interact with the two components simultaneously $[33,34]$. Even under weak interaction, clay has been reported to act as coupling agent among the polymer constituents $[35,36]$.

Regarding the SEM images of LDPE/SEBS-MA blend and nanocomposite (Figures 4(e) and 4(g)), the surface texture 
appears to be more homogenously dispersed and domains are stretched alongside each other, signaling a smooth and strong interaction between the two polymers. This is probably due to the refinement of the SEBS backbone by grafted MA. Lower viscosity ratio of SEBS-MA also would induce a change of hydrodynamic stresses during the mixing and enhance the refinement by improving the phase separation kinetics and decreasing the interfacial tension [37]. However, the immiscibility in the blend comes from the polystyrene blocks of the elastomer phase which is highly incompatible with LDPE. Therefore, the refinement of ethylene-butylene midblock of the elastomer cannot dramatically change its mixing behavior. It would, however, make the elastomer phase more attractive towards clay, promote the melt intercalation process, and accelerate the clay transportation.

It appears that the localization of clay and its possible selective interaction with the blend matrix constituents controls the morphology of the final nanocomposite. It is well-recognized that the localization of the nanoparticles is mostly determined during the mixing stage and further in the melting process. In low viscosity blends, the thermodynamic preferential attraction between nanoparticles and blend constituents determines the localization of nanoparticles, whereas, for higher viscosity, kinetic parameters such as sequence of feeding and viscosity difference of the components are dominating.

Direct feeding was used to prepare the samples; however, clay was available in the form of masterbatch, meaning that it had already been mixed with polyethylene. This order of the component mixing directly influences the clay distribution and preferential localization since polyethylene is the less favorable phase for clay to be distributed in due to the polarity difference and thermodynamic attraction. In a binary system of clay and SEBS matrix, it was shown that clay nanoparticles would locate into polystyrene (PS) cylinders of SEBS and further into poly(ethylene-co-butylene) (PEB) blocks in case of SEBS-MA [38]. With a narrow range of viscosity difference between the two polymer components, the interfacial energy becomes the main parameter determining the direction of redistribution of the nanoparticle [39-41]. Therefore, there is a great chance that during the melt processing clay would be transported from polyethylene phase to the elastomer phase. A similar phenomenon was reported for carbon black nanoparticles and assumed to be the only feasible approach $[42,43]$. Also in another study Elias et al. [44] reported that the hydrophilic silica would transfer from polypropylene to polystyrene phase during the melt mixing. Later, they reported the same mechanism for silica in polypropylene/ethylene vinyl acetate (EVA) blend [45]. As a result of this transportation the coalescence mechanism is obstructed and the polymer domains shrink into smaller size.

To evaluate this hypothesis, TEM observation was also conducted on LDPE/SEBS/5C sample, as illustrated in Figure 5. As can be seen, the orientation of clay sheets is hugely affected by the cocontinuous structure of the blend matrix. Clay stacks and separated layers can be spotted in both phases that confirm the nanofiller's transportation; however, they are mainly located in the interface. This was expected since the mixing time do not exceed a few minutes
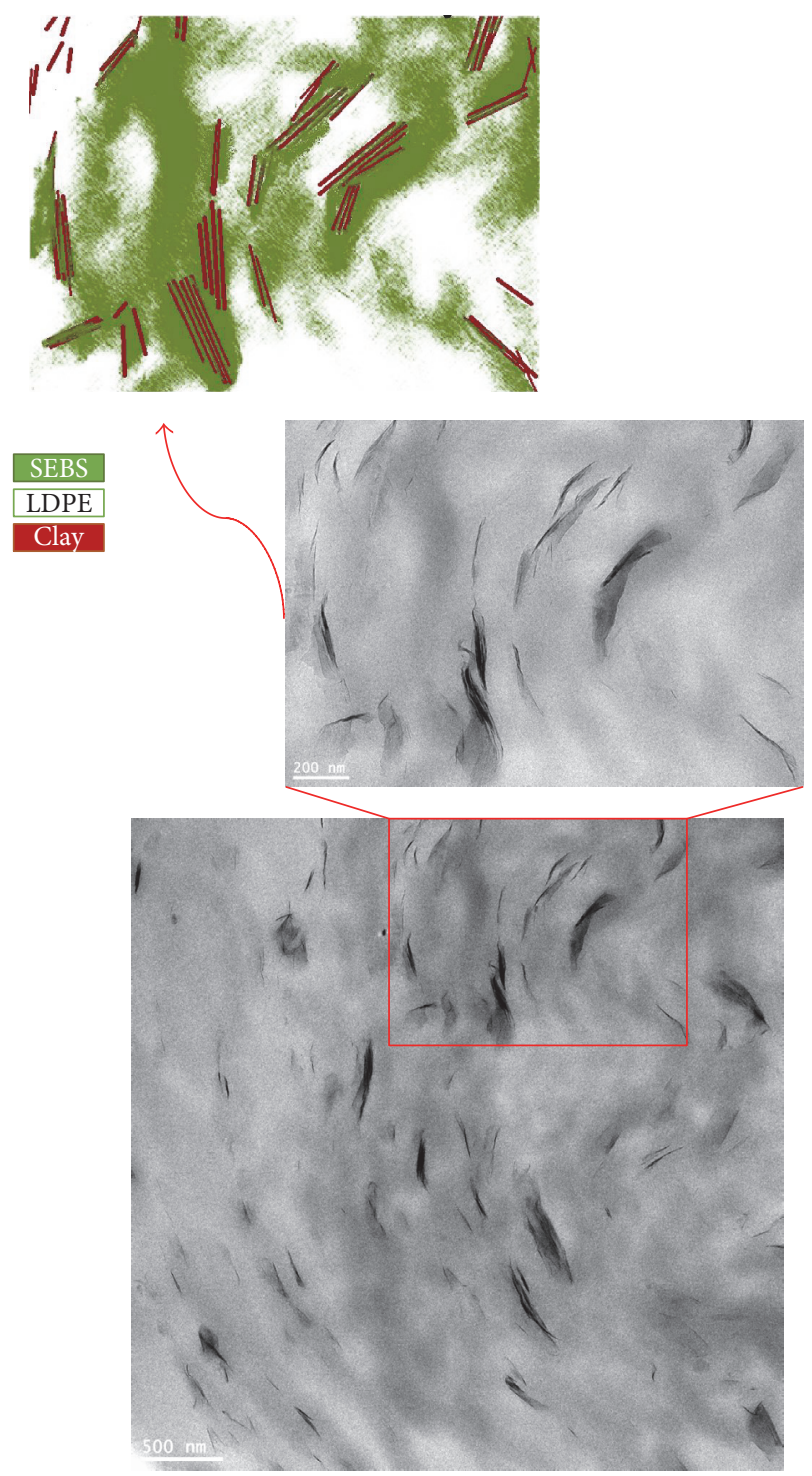

FIGURE 5: TEM micrograph of LDPE/SEBS/5C (schematic phase representation on top).

and is well lower than the Brownian diffusion time required for clay to reach the preferred localization. Also the high aspect ratio of clay reduces the speed of the transportation. For the same reason the chance of clay getting stuck in the interface of the two phases is high, where it also happens to be the area with low interfacial energy. Helal et al. [46] estimated the wetting coefficient of $\mathrm{ZnO}$ nanoparticles in PE/SEBS-MA blend and reported that the nanoparticles should be mainly localized in SEBS-MA phase and probably at the interface PE/SEBS-MA. This conclusion can also be applied here since the values of surface tension for $\mathrm{ZnO}$ and organomodified clay are close to each other.

3.3. Rheological Properties. To have more insight of the dispersion of the clay and the morphology of the blends and nanocomposites at larger scale, Small Amplitude Oscillatory Shear (SAOS) test has been conducted. 


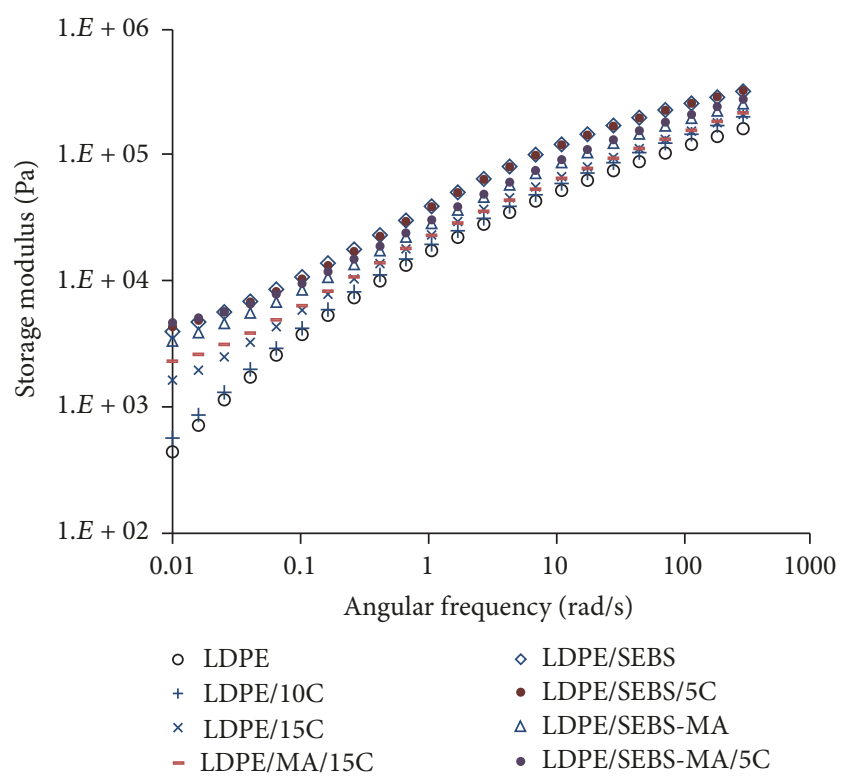

FIGURE 6: SAOS measurements of LDPE, SEBS blends, and clayreinforced nanocomposites: storage modulus $\left(G^{\prime}\right)$ as function of angular frequency $(\omega)$.

Figure 6 shows plots of storage modulus of LDPE and its blends and nanocomposites as a function of angular frequency. For neat LDPE a predictable terminal behavior is seen with a high slope and drop of the modulus at low frequencies. Similar behavior was obtained with the addition of nanoparticle up to $5 \%$ of clay where the plots of nanocomposites overlap the LDPE (not shown here) and show a homopolymer-like terminal behavior. This hints a relatively weak interfacial interaction of clay with LDPE, as was seen in SEM micrographs. Therefore, it is believed that within this range the nanoparticles' contribution is limited to the hydrodynamic effect. At $10 \%$ loading of clay (LDPE/10C) the curve slightly shifts to higher values. At $15 \%$ loading of clay (LDPE/15C) the increase is much larger and a plateau of storage modulus can be seen at low frequencies. At this point the rheological percolation threshold has been reached and nanocomposite exhibits a liquid-solid transition (LST) $[47,48]$. The increase of elasticity can be originated from the three-dimensional network formed by the clay-clay and/or clay-LDPE interaction and the resulting limitation in the molecular motion of the polymer which inclines the plot towards a solid-like response $[49,50]$. A similar behavior has been reported for nanoparticles other than clay [51-55]. In case of the nanocomposite containing compatibilizer (LDPE/MA/15C) this change of behavior is more pronounced. The low-frequency solid body response of LDPE/MA/15C nanocomposite is stronger than that of LDPE/15C. MA with lower molecular weight can easily enter the clay galleries and form a stronger interaction with the hydroxyl group on the clay layer $[56,57]$. This compatibilizing effect of MA increases the degree of interfacial interaction between LDPE/MA matrix and clay tactoids. As a result, due to the enhanced polymer intercalation the effective volume fraction of clay increases and consequently higher degree of clay dispersion is achieved. This is in accordance with the XRD pattern.

A general look at the storage modulus plots for blends and their nanocomposites represents a consistent increase through the whole range and especially in low frequencies. Due to the high level of heterogeneity in block copolymers their rheological behavior is strongly related to the phaseseparated morphology and it is brought into the blend. The low-frequency increase in the storage modulus is as a result of the characteristic nonterminal behavior of block copolymers and/or possible presence of droplets that deform and increase the elasticity [58]. It has been proposed that the dominant parameter in determining the rheology behavior of cocontinuous blends is the components' contribution and it is rarely dependent on the morphology [59]. In fact, in the case of LDPE/SEBS blend this factor is either so strong that the introducing $5 \%$ of clay does not appear to change it or still there is a weak interfacial interaction between clay and the blend matrix similar to the binary nanocomposite. In the matrix of LDPE/SEBS-MA, however, clay noticeably enhances the storage modulus where its slope approaches zero towards low frequencies. Nanofillers dispersed in each phase increase the viscosity of that phase, but more importantly those located in the interface of the two phases change the morphology of the blend by suppressing the coalescence of the blend as was seen by the downsizing effect in SEM micrographs. This will enable the LDPE/SEBS-MA matrix to form a strong network with clay, most likely due to the interaction of functional groups of clay with the maleic anhydride groups grafted on the backbones of SEBS-MA [27]. Also due to the lower viscosity of SEBS-MA, platelets and/or tactoids of clay are more easily transported, localized, and dispersed in the elastomer phase. This improved degree of dispersion of clay helps forming a stronger percolated network structure and showing such a pronounced pseudosolid-like behavior [60-62].

3.4. AC Short-Term Breakdown Strength. A two-parameter Weibull distribution was used to retrieve the dielectric breakdown data of blends and nanocomposites via commercial software. Figure 7 exhibits the plots of AC short-term breakdown strength of LDPE/clay nanocomposites with different thicknesses alongside with a column chart to compare the Weibull characteristic breakdown strengths $(\alpha)$, which represent the scale parameter of the Weibull distribution, that is, the 63.2 th percentile. Scale and shape parameters together with the $95 \%$ confidence intervals for each sample are listed in Table 2. From Figure 7(a) it can be found that when having an average thickness of $140 \mu \mathrm{m}$, all nanocomposite samples show improved breakdown strength. The characteristic breakdown strength for neat LDPE is $206 \mathrm{kV} \mathrm{mm}^{-1}$, while it goes up upon addition of clay to $227 \mathrm{kV} \mathrm{mm}^{-1}$ for $1 \%$ incorporation of clay and to $248 \mathrm{kV} \mathrm{mm}^{-1}$ when $2.5 \%$ of clay is incorporated. At maximum improvement it reaches $266 \mathrm{kV} \mathrm{mm}^{-1}$ for nanocomposite sample containing $5 \%$ of clay, showing almost $30 \%$ improvement, and then drops to 225 and $223 \mathrm{kV} \mathrm{mm}^{-1}$ for LDPE/10C and LDPE/15C samples, respectively.

Overall breakdown strength is enhanced at low nanoclay loadings up to $5 \%$ where it reaches the maximum but 


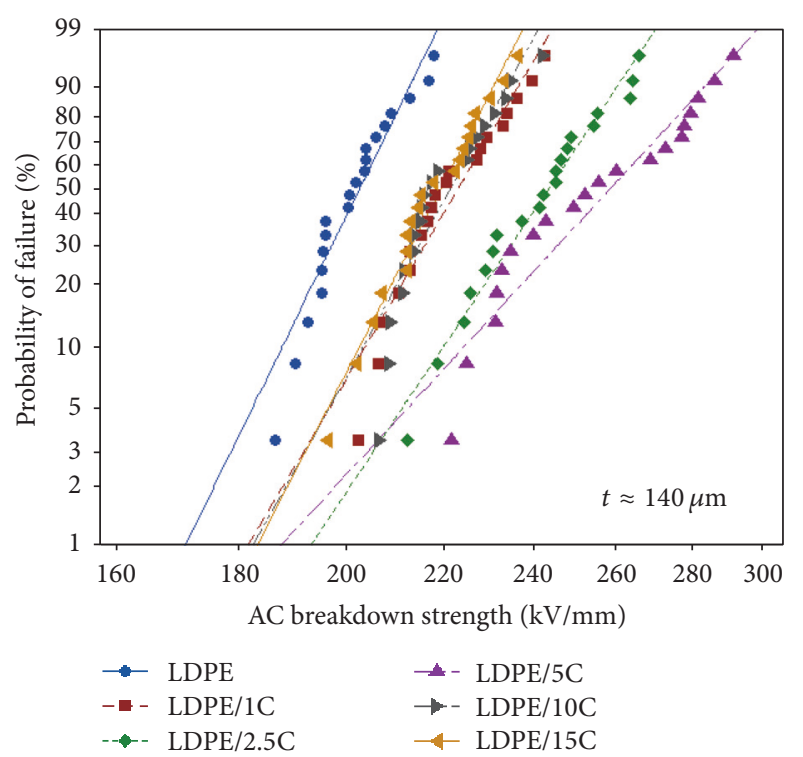

(a)

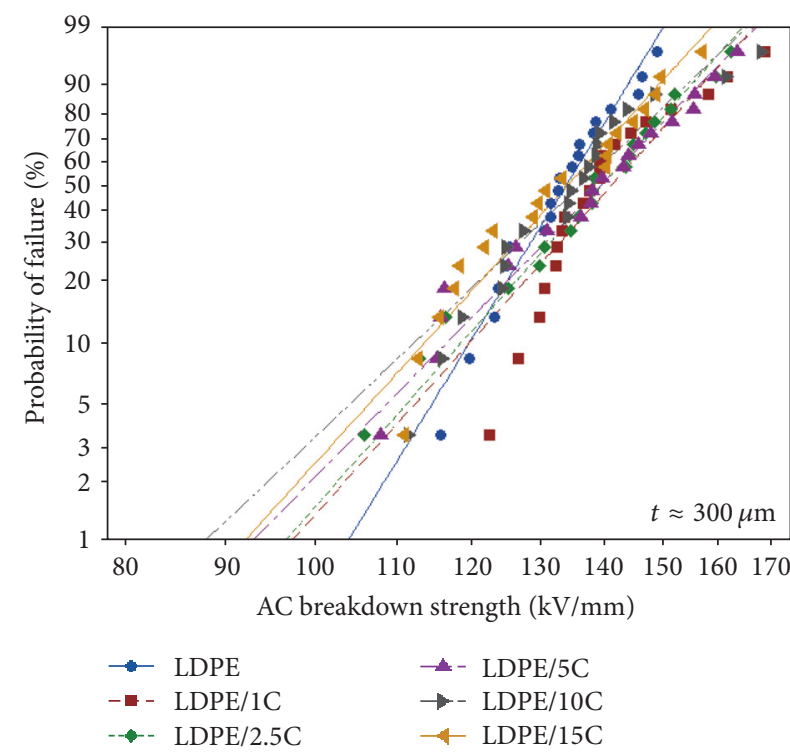

(c)

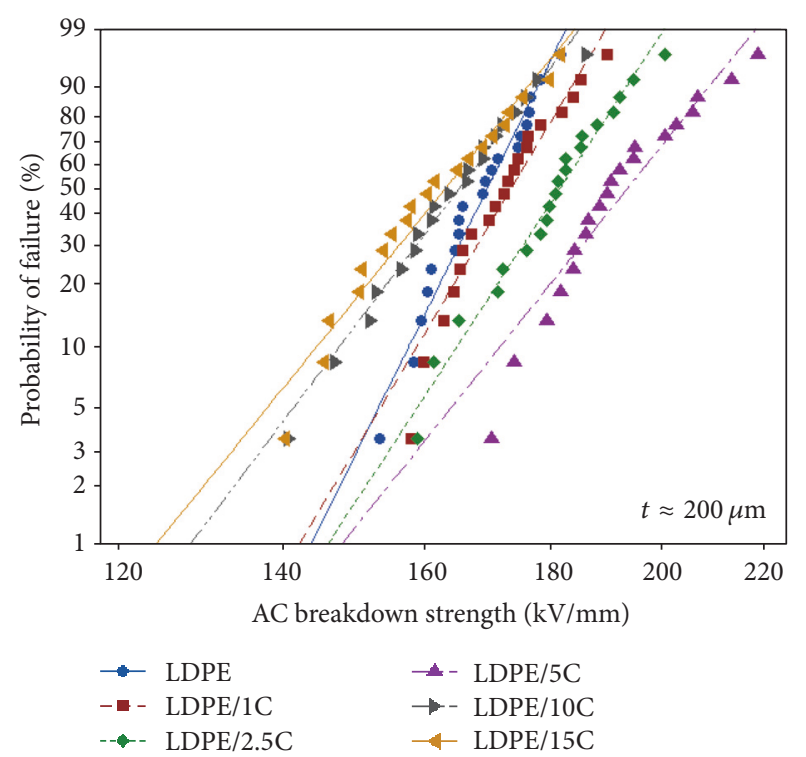

(b)

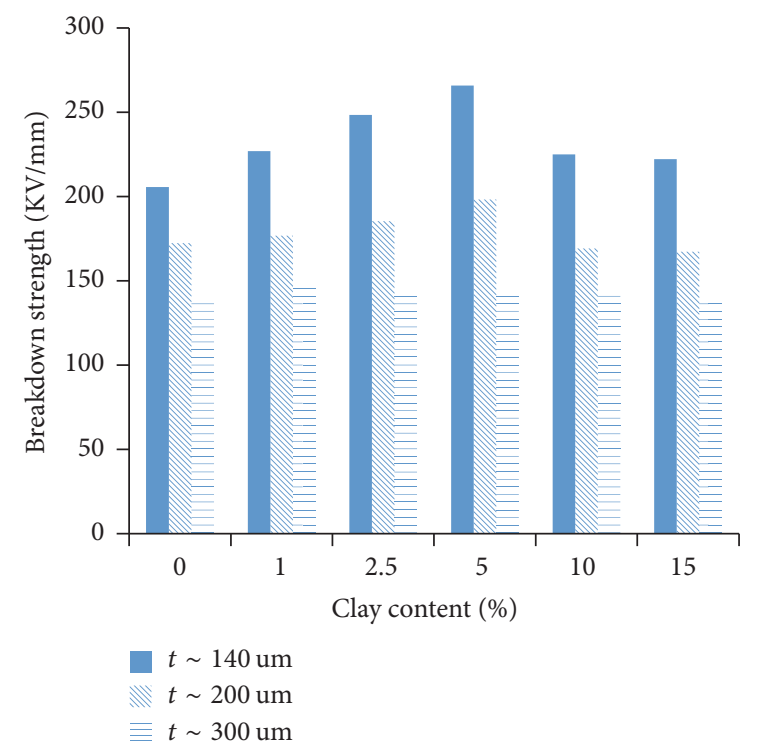

(d)

Figure 7: Weibull probability plots of LDPE/clay nanocomposites with different thicknesses: (a) $140 \mu \mathrm{m}$, (b) $200 \mu \mathrm{m}$, and (c) $300 \mu \mathrm{m}$. Comparison of the characteristic breakdown strength $(\mathrm{d})$.

decreased beyond a certain value. Consequently, there is an optimum loading of clay beyond which the enhancement is diminished. A similar trend was seen in other works $[63,64]$. Under AC condition, the direction of the charge carrier transportation keeps changing back and forth which results in local trapping and charge accumulation in the areas close to the electrodes. Therefore, the electric field is enhanced more between the interface of the electrodes and the specimen where breakdown tends to initiate and propagate through the bulk. This suggests that the improvement of AC breakdown strength upon incorporation of clay may be originated from the delaying in the process of charge transfer between electrodes through the material. Layered clay silicates despite having weak interfacial interaction with the polymer matrix would postpone breakdown by creating a tortuous path between and around themselves for charge carriers to reach the opposite electrodes [65].

The influence of clay on improving the breakdown strength of polymers has been widely discussed among researchers. Zazoum et al. [15] observed a consistent improvement of dielectric breakdown strength on LLDPE upon addition of clay up to $20 \%$ when $5 \%$ clay is incorporated. They related the improvement to the impact of the interface between the polymer matrix and the nanoclay on the space charge distribution and charge densities. They also explained the further improvement on sample having compatibilizer 


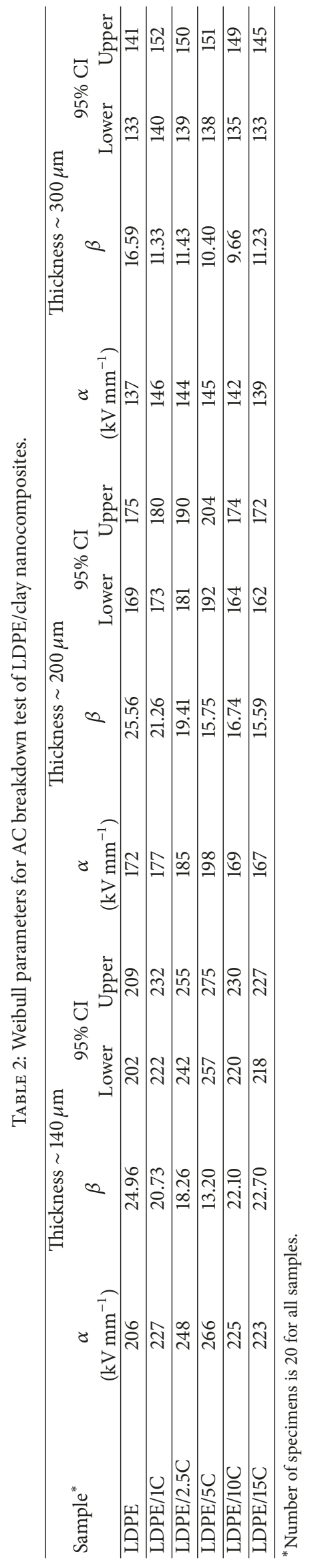


to the possible change of microstructure. Thelakkadan et al. [66] suggested that clay layers act as scattering sites for the charge carriers. During the scattering, the charges transfer their energy to nanoparticles and lose momentum. However, the nanoparticles are closely packed and do not involve in the breakdown process; therefore it requires additional voltage. This also suggests that the highest improvement happens when nanoclay is in the exfoliated state.

Liao et al. [67] investigated the electrical properties of LDPE composites containing various contents of montmorillonite. They found out that the AC breakdown strength increased when 1, 3, and 5\% of MMT are incorporated, with the maximum improvement by $11 \%$ in case of $1 \%$ incorporation of MMT. Shah et al. [68] witnessed a massive $60 \%$ and $80 \%$ improvement in the dielectric breakdown strength of high density polyethylene (HDPE) upon addition of $5 \mathrm{wt} \%$ of unmodified and organomodified clay, respectively. They assumed that the exfoliated and intercalated clay platelets distribute the electric stress and increase the path length for the breakdown. They concluded that the modification of clay with quaternary ammonium compound reduces the surface energy of the clay platelets making the intercalation of polymer molecules more feasible.

Moreover, Ghosh et al. [69] reported a remarkable 84\% improvement in the dielectric breakdown strength upon incorporation of only $0.2 \mathrm{wt} \%$ unmodified nanoclay into a poly(vinylidene fluoride) (PVDF) matrix. They observed a layer-by-layer structure of nanoclay within the PVDF matrix and hypothesized that the formation of the tortuous path between the electrodes blocks the path of the applied electric field and enhances the breakdown strength. This barrier effect has been shown to be maximum when the layers are oriented perpendicular to the field.

Also the orientation of clay layer can add to the magnitude of the improvement. Tomer et al. [70] studied the alignment effect of nanoclay on electrical properties of polyethylene. They reported that when $6 \%$ nanoclay is randomly distributed, the characteristic DC breakdown strength is not improved and the shape parameter is reduced from 21 to 7 with respect to the original matrix. However, when nanoclay is oriented the breakdown strength increases by $23 \%$ and the reduction in shape parameter is negligible. They hypothesized that the randomness acts as defect initiators, promoting electron tree inception, whereas the orientation of filler frustrates the progress of electrical treeing, by offering more tortuous paths to treeing and possessing larger populations and more structured scattering centers. In their recent work they quantified the effect of orientation and confirmed the barrier effect [71]. Bulinski et al. [72] challenged the type of nanoclay and concluded that polypropylene nanocomposite shows higher breakdown strength when it is reinforced with synthetic clay than with natural clay. They stated that this discrepancy goes to the degree of pureness, and the slightly lower improvement for natural clay is due to the negative effects of the impurities.

Studies on the influence of nanoparticles on the breakdown strength of polymers have not been limited to clay. A huge part of the recent works was dedicated to the polymeric nanocomposites containing silica nanoparticles.
The incorporation of nanosilica is widely reported to decrease the AC and DC breakdown strength of polymers [73-80]. However, there are some reports indicating no change $[81,82]$ or even improvement on the breakdown strength [83-85]. Readers are referred to a review on the effects of addition of nanoreinforcements on dielectric breakdown properties of polymers that has been published by Li et al. in 2010 [11]. Later, they published another review [17] with a comprehensive look into breakdown mechanism of nanocomposites.

From Figure 7 it is also clear that when the thickness of specimens increases the breakdown strength significantly decreases. For neat LDPE, $\alpha$ drops to $172 \mathrm{kV} \mathrm{mm}^{-1}$ and $137 \mathrm{kV} \mathrm{mm}^{-1}$ for samples with $200 \mu \mathrm{m}$ and $300 \mu \mathrm{m}$ thicknesses, respectively. Nanocomposites also show reduced breakdown strength to the point where no significant improvement is detected with the thickest samples. The reduction of breakdown strength with sample thickness is a general trend for solid dielectrics. It is often related to the greater density of defects within the material [86]. Breakdown is believed to initiate from defects where electrons can gain enough energy since the free path length in insulating polymers is short and cannot be easily destroyed by electron avalanche [87]. These defects include preexisting discontinuities and defects generated while under electric field. The number of defects in the pathways of charge carriers is higher in thicker samples which facilitate the percolation path development, thus lowering the breakdown strength [88-90].

When modeling the breakdown mechanism, researchers have incorporated the empirical thickness dependence using a prefactor term in Lorentz relation firstly introduced by Klein and Gafni [91]. However, very recently McPherson [92] challenged this long-term belief. He stated that the reduction in breakdown strength of dielectric towards higher thicknesses comes from the reduction in bond strength as a result of higher electric field within the thicker dielectrics. He claimed that bond weakening leads to lower breakdown strength in thicker dielectrics and is independent of actual bond-breakage mechanism.

On higher loading of clay, the reduction in breakdown strength is more pronounced. This is because, with increasing amount of clay, chance of particle agglomeration increases which adds to the defect density. Electric field is enhanced around these agglomerates and eventually advances the breakdown [93-95]. In samples with thickness of $200 \mu \mathrm{m}$ (Figure 7(b)) this effect dominates the mechanism, neutralizes the improvement of clay, and takes $\alpha$ below the neat LDPE. Here the saturation effect happens at $5 \%$ of clay, above which the breakdown strength is heavily diminished. With $300 \mu \mathrm{m}$ of thickness (Figure 7(c)), the general defect density is large enough to solely dominate the breakdown mechanism and is independent of agglomeration effect of clay.

According to Table 2, Weibull shape parameter $(\beta)$ is maximum for neat LDPE for all series but significantly decreases upon incorporation of clay. This is most likely originated from an evolution of the sensitivity of the measurement to defects which speeds up the breakdown and increases the unreliability. This scattering probability is mostly determined by the presence of clay tactoids boundaries, as was evidence in SEM images, and the possible agglomerates. 


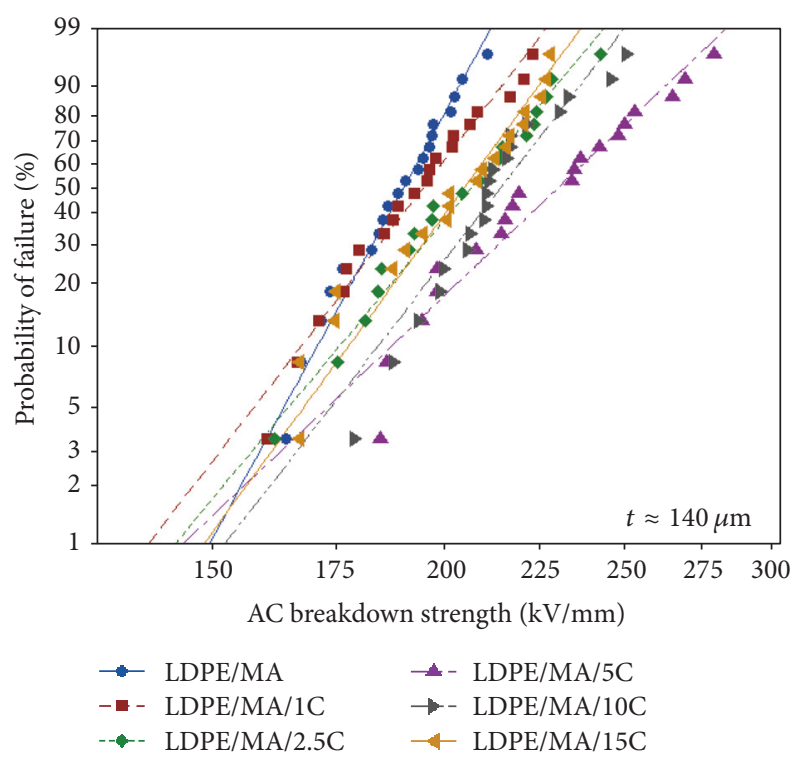

(a)

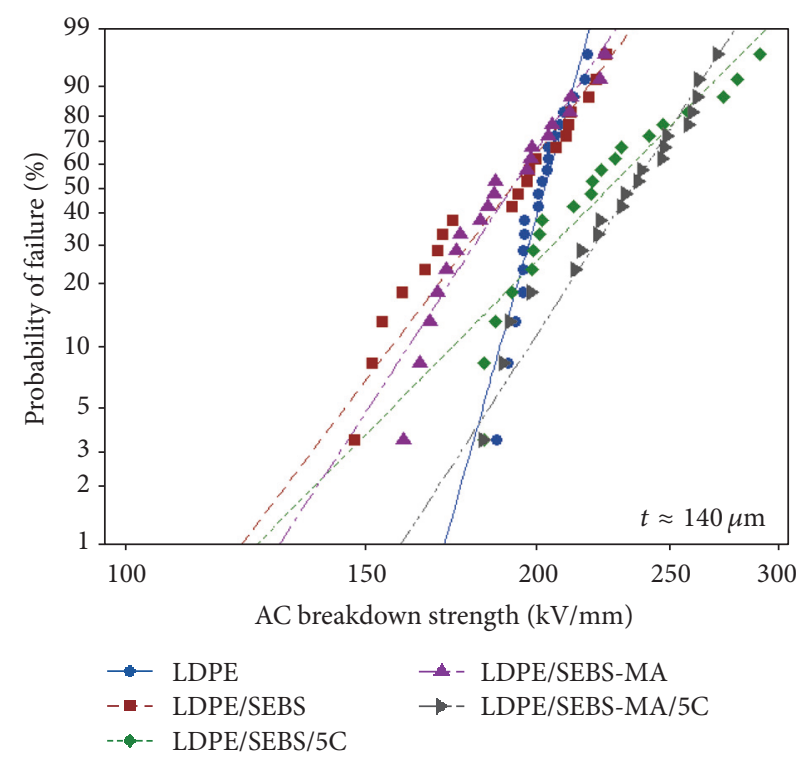

(b)

FIGURE 8: Weibull probability plots of LDPE/MA/clay nanocomposites (a) and LDPE/SEBS blends and nanocomposites (b).

Figure 8 exhibits the Weibull probability plots for AC breakdown strength of a series of LDPE/Clay nanocomposites containing $5 \mathrm{wt} \% \mathrm{MA}$ as compatibilizer (a) and blends of LDPE and two types of SEBS along with their corresponding nanocomposites containing 5\% of clay (b). Comparing to the original LDPE/Clay nanocomposites, here more or less a similar trend in increasing the breakdown strength can be seen for samples containing MA. Saturation happens at $5 \%$ of clay and then reduces but still remains above the neat LDPE. However, the improvement is not significant as to compare when MA is not incorporated. This means the addition of MA compatibilizer was unnecessary and does not affect the breakdown strength enhancement and yet diminishes it to some degree.

Regarding the AC breakdown strength of blends of LDPE with SEBS elastomers (Figure 8(b)), a noticeable reduction is seen comparing to the neat LDPE. $\alpha$ is down to $199 \mathrm{kV} \mathrm{mm}^{-1}$ for LDPE/SEBS and to $198 \mathrm{kV} \mathrm{mm}^{-1}$ for LDPE/SEBS-MA, while $\beta$ is significantly reduced. This can be explained by the dilution effect, as neat SEBS polymer generally possesses lower breakdown value than the neat LDPE and according to the rule of mixture for plastics, LDPE/SEBS blend is expected to have lower breakdown strength [96]. The lower breakdown value for SEBS elastomer probably comes from its lower Young's modulus [97], where electromechanical tensile strength generated orthogonal to the field during breakdown mode would induce more voids and crack propagation in a similar manner to that caused by mechanical stress [98]. Upon addition of $5 \%$ clay, the characteristic breakdown strengths of blends significantly increase, similar to the result of original LDPE/clay nanocomposite.

3.5. DC Short-Term Breakdown Strength. Figure 9 compares the DC breakdown strength of blends and nanocomposites of LDPE. Table 3 lists the statistical variables of the mentioned
TABLE 3: Weibull parameters for DC breakdown test of LDPE/clay blends and nanocomposites.

\begin{tabular}{|c|c|c|c|c|c|}
\hline \multirow[t]{2}{*}{ Sample } & \multirow[t]{2}{*}{$\begin{array}{l}\text { Number of } \\
\text { specimens }\end{array}$} & \multirow[t]{2}{*}{$\begin{array}{c}\alpha \\
\left(\mathrm{kVmm}^{-1}\right)\end{array}$} & \multirow[t]{2}{*}{$\beta$} & \multicolumn{2}{|c|}{$\begin{array}{c}95 \% \\
\text { confidence } \\
\text { intervals }\end{array}$} \\
\hline & & & & Lower & Upper \\
\hline LDPE & 8 & 470 & 19.87 & 453 & 478 \\
\hline LDPE/1C & 8 & 387 & 10.77 & 361 & 414 \\
\hline $\mathrm{LDPE} / 2.5 \mathrm{C}$ & 8 & 439 & 11.23 & 412 & 469 \\
\hline LDPE/5C & 8 & 366 & 9.33 & 338 & 396 \\
\hline LDPE/10C & 8 & 337 & 9.54 & 312 & 364 \\
\hline LDPE/15C & 8 & 294 & 11.16 & 275 & 314 \\
\hline LDPE/SEBS & 8 & 386 & 10.14 & 359 & 415 \\
\hline LSPE/SEBS/5C & 8 & 276 & 7.02 & 248 & 306 \\
\hline $\begin{array}{l}\text { LDPE/SEBS- } \\
\text { MA }\end{array}$ & 8 & 385 & 11.55 & 361 & 410 \\
\hline $\begin{array}{l}\text { LDPE/SEBS- } \\
\text { MA/5C }\end{array}$ & 8 & 309 & 7.09 & 279 & 343 \\
\hline
\end{tabular}

plots. One can see that the DC breakdown strength of neat LDPE is as high as $470 \mathrm{kV} / \mathrm{mm}$. From Figure 9(a), it goes down upon addition of clay for all the formulations and sinks to around $294 \mathrm{kV} / \mathrm{mm}$ at highest amount of nanofiller. The DC breakdown strength decreases with increased loading of clay. The only comparable result is seen for $2.5 \%$ loading of clay which shows a characteristic DC breakdown strength of $439 \mathrm{kV} / \mathrm{mm}$. Blends of LDPE with both types of SEBS also show a noticeable $18 \%$ reduction in DC breakdown strength with having $\alpha$ around $386 \mathrm{kV} / \mathrm{mm}$. Further reductions are seen for the corresponding nanocomposites containing $5 \%$ of clay. 


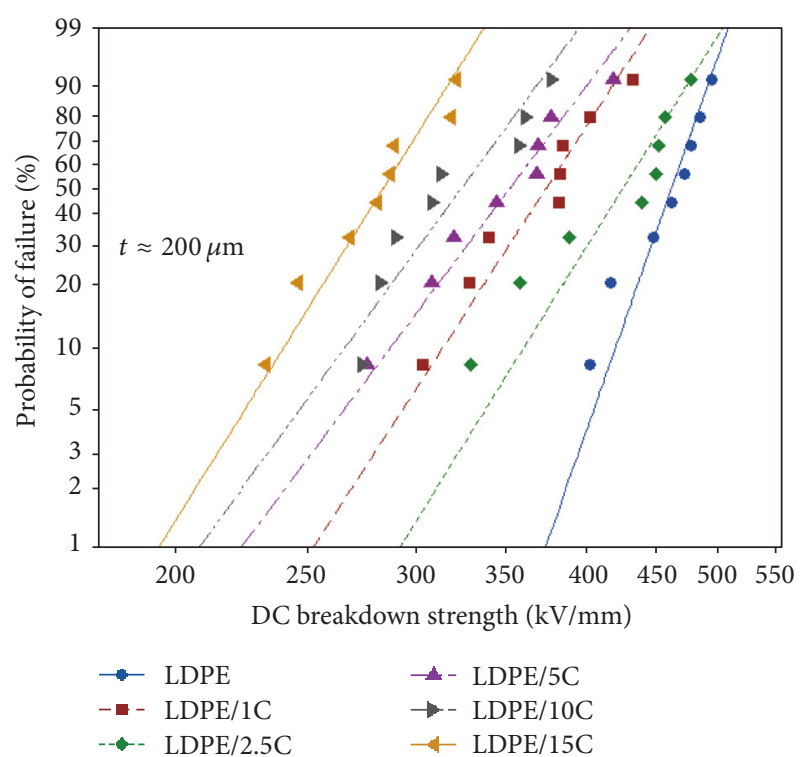

(a)

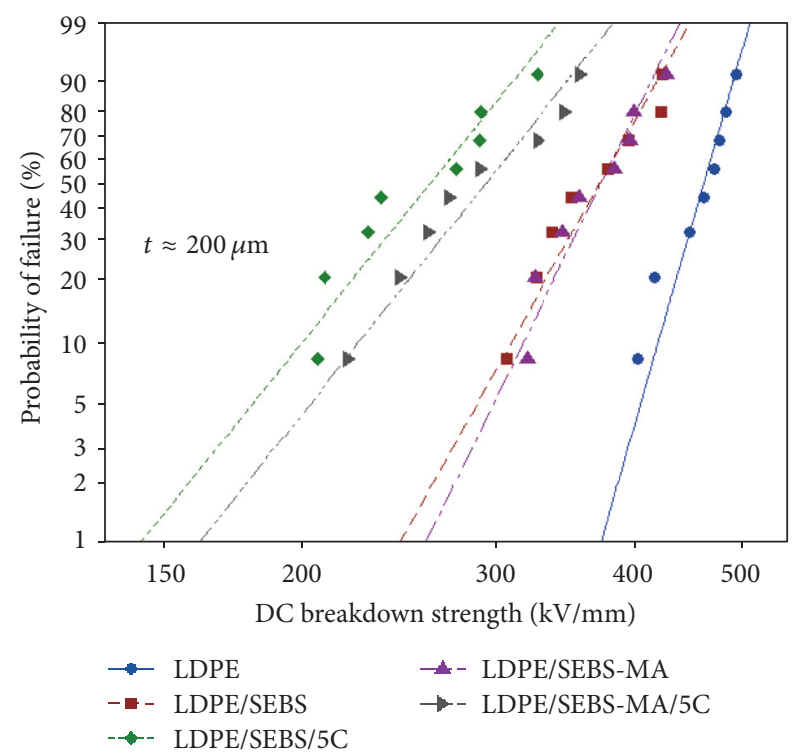

(b)

FIGURE 9: Weibull plots of LDPE nanocomposites reinforced with clay (a) and blends of LDPE and two types of SEBS along with their corresponding nanocomposites containing $5 \%$ of clay.

Unlike the AC breakdown strength, the DC breakdown trend is completely different. It is strongly sensitive to the type of matrix and the amount of nanofiller and in all cases the DC breakdown strength is lower than that of neat LDPE. This behavior is not strange and has been reported before [93, 99-101]. The reduction in DC breakdown strength could be originated from several parameters and it is beyond the agglomeration effect of nanofiller which was the primary reason for reduction in AC breakdown strength. Nevertheless, the particle agglomeration still remains as a simple explanation and its effect might be more pronounced on DC breakdown strength due to the higher required voltage for breakdown.

The increased charge trapping as a result of the introduction of clay can also contribute to the reduction of DC breakdown strength in nanocomposites. Charges can become stationary in trap sites around the nanoparticle, also known as space charge effect. This will increase the field inside the material and advance the breakdown. Space charge is not an issue for AC systems where the oscillating polarity reversal does not allow sufficient time for charge to be trapped. The poor dispersion of clay tactoids also adds to the magnitude of charge trapping and the breakdown strength goes to lower amount with increasing in clay loading. Thermal breakdown is another possible process of DC breakdown for LDPE [102], which under DC supply can be affected largely by the electrical conductivity. As the voltage goes up much more before breakdown comparing to AC test, it is possible that thermal instability of the material advances the breakdown.

\section{Conclusion}

In this study dielectric breakdown properties of clay-based LDPE nanocomposites have been investigated as one of the most important parameters to evaluate the potentials to replace the current $\mathrm{HV}$ cable insulating materials. Clay layers have been shown to be widely dispersed and distributed in LDPE matrix, especially when a compatibilizer is utilized. As a result, a remarkable improvement on the AC breakdown strength of the nanocomposites has been achieved. This was maximized when $5 \%$ of clay was incorporated, while the degree of improvements in lower amount of clay is still significant. It suggests that organomodified clay has the potentials to make electrical properties of LDPE matrix comparable to currently used XLPE-type cable insulation materials considering its easy access and cheap price.

The use of immiscible blends of LDPE with two types of SEBS copolymer also showed interesting results upon addition of clay. It was witnessed that clay can alter the morphology of the blend when it is firstly mixed with the polyethylene through the migration process into the elastomer phase and results in higher AC breakdown strength comparing to the unfilled blends. Considering the proven mechanical flexibility of SEBS copolymer, this type of blends does have the potentials to be used as insulating materials in HV applications.

\section{Conflicts of Interest}

The authors declare that there are no conflicts of interest regarding the publication of this paper.

\section{Acknowledgments}

The authors acknowledge the sincere cooperation of the staff of the Laboratory of Innovation Technologies (LIT) at University of Bologna, especially Dr. Fabrizio Palmieri. 


\section{References}

[1] K. C. Kao, Dielectric Phenomena in Solids, Academic Press, 2004.

[2] H. R. Zeller, P. Pfluger, and J. Bernasconi, "High-mobility states and dielectric breakdown in polymeric dielectrics," IEEE Transactions on Dielectrics and Electrical Insulation, vol. 19, no. 3, pp. 200-204, 1984.

[3] T. Tanaka, "Dielectric breakdown in polymer nanocomposites," in Polymer Nanocomposites, pp. 113-137, Springer, 2016.

[4] L. A. Dissado and J. C. Fothergill, Electrical Degradation and Breakdown in Polymers, vol. 9, IET, 1992.

[5] A. R. Blythe and D. Bloor, Electrical Properties of Polymers, Cambridge University Press, 2005.

[6] V. A. Zakrevskii, N. T. Sudar, A. Zaopo, and Y. A. Dubitsky, "Mechanism of electrical degradation and breakdown of insulating polymers," Journal of Applied Physics, vol. 93, no. 4, pp. 2135-2139, 2003.

[7] A. K. Jonscher and R. Lacoste, "On a cumulative model of dielectric breakdown in solids," IEEE Transactions on Dielectrics and Electrical Insulation, vol. 19, no. 6, pp. 567-577, 1984.

[8] Z. Wang, T. Iizuka, M. Kozako, Y. Ohki, and T. Tanaka, "Development of epoxy/BN composites with high thermal conductivity and sufficient dielectric breakdown strength part II-breakdown strength," IEEE Transactions on Dielectrics and Electrical Insulation, vol. 18, no. 6, pp. 1973-1983, 2011.

[9] Y. Cao, P. C. Irwin, and K. Younsi, "The future of nanodielectrics in the electrical power industry," IEEE Transactions on Dielectrics and Electrical Insulation, vol. 11, no. 5, pp. 797-807, 2004.

[10] T. J. Lewis, "Nanometric dielectrics," IEEE Transactions on Dielectrics and Electrical Insulation, vol. 1, no. 5, pp. 812-825, 1994.

[11] S. Li, G. Yin, G. Chen et al., "Short-term breakdown and longterm failure in nanodielectrics: A review," IEEE Transactions on Dielectrics and Electrical Insulation, vol. 17, no. 5, pp. 1523-1535, 2010.

[12] M. Roy, J. K. Nelson, R. K. MacCrone, L. S. Schadler, C. W. Reed, and R. Keefe, "Polymer nanocomposite dielectrics-the role of the interface," IEEE Transactions on Dielectrics and Electrical Insulation, vol. 12, no. 4, pp. 629-643, 2005.

[13] J. K. Nelson, J. C. Fothergill, L. A. Dissado, and W. Peasgood, "Towards an understanding of nanometric dielectrics," in Proceedings of the IEEE Annual Report Conference on Electrical Insulation and Dielectric Phenomena, pp. 295-298, October 2002.

[14] D. Fabiani, P. Mancinelli, C. Vanga-Bouanga, M. F. Frechette, and J. Castellon, "Effect of graphene-oxide content on space charge characteristics of PE-based nanocomposites," in Proceedings of the 34th IEEE Electrical Insulation Conference (EIC '16), pp. 631-634, IEEE, June 2016.

[15] B. Zazoum, E. David, and A. D. Ngô, "Correlation between structure and dielectric breakdown in LDPE/HDPE/clay nanocomposites," ISRN Nanomaterials, vol. 2014, Article ID 612154, 9 pages, 2014.

[16] T. J. Lewis, "Interfaces are the dominant feature of dielectrics at the nanometric level," IEEE Transactions on Dielectrics and Electrical Insulation, vol. 11, no. 5, pp. 739-753, 2004.

[17] S. Li, L. Yang, W. Liu, and W. Wang, Dielectric Breakdown of Polymer Nanocomposites, 2016.

[18] W. Peng, X. Huang, J. Yu, P. Jiang, and W. Liu, "Electrical and thermophysical properties of epoxy/aluminum nitride nanocomposites: Effects of nanoparticle surface modification," Composites Part A: Applied Science and Manufacturing, vol. 41, no. 9, pp. 1201-1209, 2010.

[19] X. Huang, C. Kim, P. Jiang, Y. Yin, and Z. Li, "Influence of aluminum nanoparticle surface treatment on the electrical properties of polyethylene composites," Journal of Applied Physics, vol. 105, no. 1, Article ID 014105, 2009.

[20] L. M. Robeson, Polymer Blends, Hanser, München, Germany, 2007.

[21] M. M. Coleman, P. C. Painter, and J. F. Graf, Specific Interactions and the Miscibility of Polymer Blends, CRC Press, 1995.

[22] P. Pötschke and D. R. Paul, "Formation of co-continuous structures in melt-mixed immiscible polymer blends," Journal of Macromolecular Science, Part C: Polymer Reviews, vol. 43, no. 1, pp. 87-141, 2003.

[23] G. Filippone, N. T. Dintcheva, F. P. La Mantia, and D. Acierno, "Selective localization of organoclay and effects on the morphology and mechanical properties of LDPE/PA11 blends with distributed and co-continuous morphology," Journal of Polymer Science Part B: Polymer Physics, vol. 48, no. 5, pp. 600-609, 2010.

[24] G. P. Kar, S. Biswas, R. Rohini, and S. Bose, "Tailoring the dispersion of multiwall carbon nanotubes in co-continuous PVDF/ABS blends to design materials with enhanced electromagnetic interference shielding," Journal of Materials Chemistry A, vol. 3, no. 15, pp. 7974-7985, 2015.

[25] S. P. Pawar and S. Bose, "Peculiar morphological transitions induced by nanoparticles in polymeric blends: Retarded relaxation or altered interfacial tension?" Physical Chemistry Chemical Physics, vol. 17, no. 22, pp. 14470-14473, 2015.

[26] S. Pavlidou and C. D. Papaspyrides, "A review on polymerlayered silicate nanocomposites," Progress in Polymer Science, vol. 33, no. 12, pp. 1119-1198, 2008.

[27] E. Helal, N. R. Demarquette, E. David, and M. Frechette, "Evaluation of dielectric behavior of polyethylene/thermoplastic elastomer blends containing zinc oxide $(\mathrm{ZnO})$ nanoparticles for high voltage insulation," in Proceedings of the 34th IEEE Electrical Insulation Conference (EIC '16), pp. 592-595, IEEE, June 2016.

[28] M. Alexandre and P. Dubois, "Polymer-layered silicate nanocomposites: preparation, properties and uses of a new class of materials," Materials Science and Engineering: R: Reports, vol. 28, no. 1, pp. 1-63, 2000.

[29] M. Eesaee and A. Shojaei, "Effect of nanoclays on the mechanical properties and durability of novolac phenolic resin/woven glass fiber composite at various chemical environments," Composites Part A: Applied Science and Manufacturing, vol. 63, pp. 149-158, 2014.

[30] M.-J. Dumont, A. Reyna-Valencia, J.-P. Emond, and M. Bousmina, "Barrier properties of polypropylene/organoclay nanocomposites," Journal of Applied Polymer Science, vol. 103, no. 1, pp. 618-625, 2007.

[31] J. Tokarský, L. Kulhánková, L. Neuwirthová et al., “Highly anisotropic conductivity of tablets pressed from polyanilinemontmorillonite nanocomposite," Materials Research Bulletin, vol. 75, pp. 139-143, 2016.

[32] L. As'habi, S. H. Jafari, B. Baghaei, H. A. Khonakdar, P. Pötschke, and F. Böhme, "Structural analysis of multicomponent nanoclay-containing polymer blends through simple model systems," Polymer Journal, vol. 49, no. 8, pp. 2119-2126, 2008.

[33] L. Li, W. Yong, X. Fangming, Y. Li, H. Liang, and Z. Zuowan, "Effects of functionalized multiwalled carbon nanotubes on the 
morphologies and mechanical properties of PP/EVA blend," Journal of Polymer Science Part B: Polymer Physics, vol. 47, no. 15, pp. 1481-1491, 2009.

[34] S. S. Ray, S. Pouliot, M. Bousmina, and L. A. Utracki, "Role of organically modified layered silicate as an active interfacial modifier in immiscible polystyrene/polypropylene blends," Polymer, vol. 45, no. 25, pp. 8403-8413, 2004.

[35] M. Si, T. Araki, H. Ader et al., "Compatibilizing bulk polymer blends by using organoclays," Macromolecules, vol. 39, no. 14, pp. 4793-4801, 2006.

[36] Z. Fang, Y. Xu, and L. Tong, "Effect of clay on the morphology of binary blends of polyamide 6 with high density polyethylene and HDPE-graft-acrylic acid," Polymer Engineering \& Science, vol. 47, no. 5, pp. 551-559, 2007.

[37] L. Minkova, H. Yordanov, S. Filippi, and N. Grizzuti, "Interfacial tension of compatibilized blends of LDPE and PA6: the breaking thread method," Polymer, vol. 44, no. 26, pp. 7925-7932, 2003.

[38] E. Helal, N. R. Demarquette, L. G. Amurin, E. David, D. J. Carastan, and M. Fréchette, "Styrenic block copolymerbased nanocomposites: implications of nanostructuration and nanofiller tailored dispersion on the dielectric properties," Polymer, vol. 64, pp. 139-152, 2015.

[39] S. Asai, K. Sakata, M. Sumita, and K. Miyasaka, "Effect of interfacial free energy on the heterogeneous distribution of oxidized carbon black in polymer blends," Polymer Journal, vol. 24, no. 5, pp. 415-420, 1992.

[40] M. Sumita, K. Sakata, S. Asai, K. Miyasaka, and H. Nakagawa, "Dispersion of fillers and the electrical conductivity of polymer blends filled with carbon black," Polymer Bulletin, vol. 25, no. 2, pp. 265-271, 1991.

[41] A. L. Persson and H. Bertilsson, "Viscosity difference as distributing factor in selective absorption of aluminium borate whiskers in immiscible polymer blends," Polymer Journal, vol. 39, no. 23, pp. 5633-5642, 1998.

[42] A. E. Zaikin, R. R. Karimov, and V. P. Arkhireev, "A study of the redistribution conditions of carbon black particles from the bulk to the interface in heterogeneous polymer blends," Colloid Journal, vol. 63, no. 1, pp. 53-59, 2001.

[43] A. E. Zaikin, E. A. Zharinova, and R. S. Bikmullin, "Specifics of localization of carbon black at the interface between polymeric phases," Polymer Science Series A, vol. 49, no. 3, pp. 328-336, 2007.

[44] L. Elias, F. Fenouillot, J. C. Majeste, and P. Cassagnau, "Morphology and rheology of immiscible polymer blends filled with silica nanoparticles," Polymer, vol. 48, no. 20, pp. 6029-6040, 2007.

[45] L. Elias, F. Fenouillot, J. C. Majesté, P. Alcouffe, and P. Cassagnau, "Immiscible polymer blends stabilized with nano-silica particles: rheology and effective interfacial tension," Polymer, vol. 49, no. 20, pp. 4378-4385, 2008.

[46] E. Helal, E. David, M. Fréchette, and N. R. Demarquette, "Thermoplastic elastomer nanocomposites with controlled nanoparticles dispersion for HV insulation systems: correlation between rheological, thermal, electrical and dielectric properties," European Polymer Journal, vol. 94, pp. 68-86, 2017.

[47] P. Cassagnau, "Melt rheology of organoclay and fumed silica nanocomposites," Polymer, vol. 49, no. 9, pp. 2183-2196, 2008.

[48] Y. Song and Q. Zheng, "Linear rheology of nanofilled polymers," Journal of Rheology, vol. 59, no. 1, pp. 155-191, 2015.

[49] S. Bagheri-Kazemabad, D. Fox, Y. Chen et al., "Morphology, rheology and mechanical properties of polypropylene/ ethylene-octene copolymer/clay nanocomposites: Effects of the compatibilizer," Composites Science and Technology, vol. 72, no. 14, pp. 1697-1704, 2012.

[50] J. Ren, A. S. Silva, and R. Krishnamoorti, "Linear viscoelasticity of disordered polystyrene-polyisoprene block copolymer based layered-silicate nanocomposites," Macromolecules, vol. 33, no. 10, pp. 3739-3746, 2000.

[51] G. Gong, J. Wu, Y. Lin, C. Chan, and M. Yang, "Dynamic rheological behavior of isotactic polypropylene filled with nanocalcium carbonate modified by stearic acid coating," Journal of Macromolecular Science, Part B: Physics, vol. 48, no. 2, pp. 329343, 2009.

[52] D. Wu, L. Wu, M. Zhang, and Y. Zhao, "Viscoelasticity and thermal stability of polylactide composites with various functionalized carbon nanotubes," Polymer Degradation and Stability, vol. 93, no. 8, pp. 1577-1584, 2008.

[53] W. D. Lee, S. S. Im, H.-M. Lim, and K.-J. Kim, "Preparation and properties of layered double hydroxide/poly(ethylene terephthalate) nanocomposites by direct melt compounding," Polymer, vol. 47, no. 4, pp. 1364-1371, 2006.

[54] G. Romeo, G. Filippone, A. Fernández-Nieves, P. Russo, and D. Acierno, "Elasticity and dynamics of particle gels in nonNewtonian melts," Rheologica Acta, vol. 47, no. 9, pp. 989-997, 2008.

[55] A. S. Sarvestani, "Modeling the solid-like behavior of entangled polymer nanocomposites at low frequency regimes," European Polymer Journal, vol. 44, no. 2, pp. 263-269, 2008.

[56] N. Hasegawa and A. Usuki, "Silicate layer exfoliation in polyolefin/clay nanocomposites based on maleic anhydride modified polyolefins and organophilic clay," Journal of Applied Polymer Science, vol. 93, no. 1, pp. 464-470, 2004.

[57] M.-T. Ton-That, F. Perrin-Sarazin, K. C. Cole, M. N. Bureau, and J. Denault, "Polyolefin nanocomposites: formulation and development," Polymer Engineering \& Science, vol. 44, no. 7, pp. 1212-1219, 2004.

[58] D. J. Carastan, N. R. Demarquette, A. Vermogen, and K. Masenelli-Varlot, "Linear viscoelasticity of styrenic block copolymers-clay nanocomposites," Rheologica Acta, vol. 47, no. 5-6, pp. 521-536, 2008.

[59] H. Veenstra, P. C. J. Verkooijen, B. J. J. Van Lent, J. Van Dam, A. P. De Boer, and A. P. H. J. Nijhof, "On the mechanical properties of co-continuous polymer blends: Experimental and modelling," Polymer Journal, vol. 41, no. 5, pp. 1817-1826, 2000.

[60] B. B. Khatua, D. J. Lee, H. Y. Kim, and J. K. Kim, "Effect of organoclay platelets on morphology of nylon-6 and poly(ethyleneran-propylene) rubber blends," Macromolecules, vol. 37, no. 7, pp. 2454-2459, 2004.

[61] W. S. Chow, A. Abu Bakar, Z. A. Mohd Ishak, J. KargerKocsis, and U. S. Ishiaku, "Effect of maleic anhydride-grafted ethylene-propylene rubber on the mechanical, rheological and morphological properties of organoclay reinforced polyamide 6/polypropylene nanocomposites," European Polymer Journal, vol. 41, no. 4, pp. 687-696, 2005.

[62] R. R. Tiwari, D. L. Hunter, and D. R. Paul, "Extruder-made TPO nanocomposites. I. Effect of maleated polypropylene and organoclay ratio on the morphology and mechanical properties," Journal of Polymer Science Part B: Polymer Physics, vol. 50, no. 22, pp. 1577-1588, 2012.

[63] S. Li, G. Yin, and J. Li, "Breakdown performance of low density polyethylene nanocomposites," in Proceedings of the IEEE 10th International Conference on the Properties and Applications of Dielectric Materials (ICPADM '12), IEEE, July 2012. 
[64] S. Li, G. Yin, S. Bai, and J. Li, "A new potential barrier model in epoxy resin nanodielectrics," IEEE Transactions on Dielectrics and Electrical Insulation, vol. 18, no. 5, pp. 1535-1543, 2011.

[65] S. P. Fillery, H. Koerner, L. Drummy et al., "Nanolaminates: increasing dielectric breakdown strength of composites," ACS Applied Materials \& Interfaces, vol. 4, no. 3, pp. 1388-1396, 2012.

[66] A. S. Thelakkadan, G. Coletti, F. Guastavino, and A. Fina, "Effect of the nature of clay on the thermo-mechanodynamical and electrical properties of epoxy/clay nanocomposites," Polymer Composites, vol. 32, no. 10, pp. 1499-1504, 2011.

[67] R. Liao, G. Bai, L. Yang, H. Cheng, Y. Yuan, and J. Guan, "Improved electric strength and space charge characterization in LDPE composites with montmorillonite fillers," Journal of Nanomaterials, vol. 2013, Article ID 712543, 7 pages, 2013.

[68] K. S. Shah, R. C. Jain, V. Shrinet, A. K. Singh, and D. P. Bharambe, "High density polyethylene (HDPE) clay nanocomposite for dielectric applications," IEEE Transactions on Dielectrics and Electrical Insulation, vol. 16, no. 3, pp. 853-861, 2009.

[69] S. K. Ghosh, W. Rahman, T. R. Middya, S. Sen, and D. Mandal, "Improved breakdown strength and electrical energy storage performance of $\gamma$-poly(vinylidene fluoride)/unmodified montmorillonite clay nano-dielectrics," Nanotechnology, vol. 27, no. 21, Article ID 215401, 2016.

[70] V. Tomer, G. Polizos, C. A. Randall, and E. Manias, "Polyethylene nanocomposite dielectrics: Implications of nanofiller orientation on high field properties and energy storage," Journal of Applied Physics, vol. 109, no. 7, Article ID 074113, 2011.

[71] B. Li, C. I. Camilli, P. I. Xidas, K. S. Triantafyllidis, and E. Manias, "Structured polyethylene nanocomposites: effects of crystal orientation and nanofiller alignment on high field dielectric properties," MRS Advances, vol. 2, no. 6, pp. 363-368, 2017.

[72] A. Bulinski, S. S. Bamji, M. Abou-Dakka, and Y. Chen, "Dielectric properties of polypropylene containing synthetic and natural organoclays," in Proceedings of the IEEE International Symposium on Electrical Insulation (ISEI '10), IEEE, June 2010.

[73] K. Y. Lau, M. A. M. Piah, and K. Y. Ching, "Correlating the breakdown strength with electric field analysis for polyethylene/silica nanocomposites," Journal of Electrostatics, vol. 86, pp. 1-11, 2017.

[74] T. Krentz, M. M. Khani, M. Bell et al., "Morphologically dependent alternating-current and direct-current breakdown strength in silica-polypropylene nanocomposites," Journal of Applied Polymer Science, vol. 134, no. 1, Article ID 44347, 2017.

[75] P. Luo, S. Wang, B. Feng, Q. Mu, M. Xu, and Y. Xu, "AC breakdown strength and glass transition temperature of mesoporous silica/EP composite," in Proceedings of the 5th IEEE International Conference on High Voltage Engineering and Application (ICHVE '16), IEEE, September 2016.

[76] M. Ritämaki, I. Rytoluoto, M. Niittymaki, K. Lahti, and M. Karttunen, "Differences in AC and DC large-area breakdown behavior of polymer thin films," in Proceedings of the 1st IEEE International Conference on Dielectrics (ICD '16), pp. 1011-1014, IEEE, July 2016.

[77] I. L. Hosier, M. Praeger, A. F. Holt, A. S. Vaughan, and S. G. Swingler, "On the effect of functionalizer chain length and water content in polyethylene/silica nanocomposites: part I-dielectric properties and breakdown strength," IEEE Transactions on Dielectrics and Electrical Insulation, vol. 24, no. 3, pp. 1698-1707, 2017.
[78] K. Lau, A. Vaughan, G. Chen, I. Hosier, A. Holt, and K. Ching, "On the space charge and DC breakdown behavior of polyethylene/silica nanocomposites," IEEE Transactions on Dielectrics and Electrical Insulation, vol. 21, no. 1, pp. 340-351, 2014.

[79] I. L. Hosier, M. Praeger, A. F. Holt, A. S. Vaughan, and S. G. Swingler, "Effect of water absorption on dielectric properties of nano-silica/polyethylene composites," in Proceedings of the IEEE Conference on Electrical Insulation and Dielectric Phenomena (CEIDP '14), pp. 651-654, IEEE, October 2014.

[80] X. Huang, F. Liu, and P. Jiang, "Effect of nanoparticle surface treatment on morphology, electrical and water treeing behavior of LLDPE composites," IEEE Transactions on Dielectrics and Electrical Insulation, vol. 17, no. 6, pp. 1697-1704, 2010.

[81] T. Tanaka, "Dielectric nanocomposites with insulating properties," IEEE Transactions on Dielectrics and Electrical Insulation, vol. 12, no. 5, pp. 914-928, 2005.

[82] G. Iyer, R. S. Gorur, R. Richert, A. Krivda, and L. E. Schmidt, "Dielectric properties of epoxy based nanocomposites for high voltage insulation," IEEE Transactions on Dielectrics and Electrical Insulation, vol. 18, no. 3, pp. 659-666, 2011.

[83] L. Hui, L. S. Schadler, and J. K. Nelson, "The influence of moisture on the electrical properties of crosslinked polyethylene/silica nanocomposites," IEEE Transactions on Dielectrics and Electrical Insulation, vol. 20, no. 2, pp. 641-653, 2013.

[84] M. Takala, H. Ranta, P. Nevalainen et al., "Dielectric properties and partial discharge endurance of polypropylene-silica nanocomposite," IEEE Transactions on Dielectrics and Electrical Insulation, vol. 17, no. 4, pp. 1259-1267, 2010.

[85] M. Roy, J. K. Nelson, R. K. MacCrone, and L. S. Schadler, "Candidate mechanisms controlling the electrical characteristics of silica/XLPE nanodielectrics," Journal of Materials Science, vol. 42, no. 11, pp. 3789-3799, 2007.

[86] G. Chen, J. Zhao, S. Li, and L. Zhong, "Origin of thickness dependent dc electrical breakdown in dielectrics," Applied Physics Letters, vol. 100, no. 22, Article ID 222904, 2012.

[87] K. Theodosiou, I. Vitellas, I. Gialas, and D. P. Agoris, "Polymer films degradation and breakdown in high voltage AC fields," Journal of Electrical Engineering, vol. 55, no. 9-10, pp. 225-231, 2004.

[88] H. K. Kim and F. G. Shi, "Thickness dependent dielectric strength of a low-permittivity dielectric film," IEEE Transactions on Dielectrics and Electrical Insulation, vol. 8, no. 2, pp. 248-252, 2001.

[89] R. Degraeve, G. Groeseneken, R. Bellens et al., "New insights in the relation between electron trap generation and the statistical properties of oxide breakdown," IEEE Transactions on Electron Devices, vol. 45, no. 4, pp. 904-911, 1998.

[90] J. Sune, D. Jimenez, and E. Miranda, "Breakdown modes and breakdown statistics of ultrathin $\mathrm{SiO}_{2}$ gate oxides," International Journal of High Speed Electronics and Systems, vol. 11, no. 3, pp. 789-848, 2001.

[91] N. Klein and H. Gafni, "The maximum dielectric strength of thin silicon oxide films," IEEE Transactions on Electron Devices, vol. 13, no. 2, pp. 281-289, 1966.

[92] J. W. McPherson, "On why dielectric breakdown strength reduces with dielectric thickness," in Proceedings of the IEEE International Reliability Physics Symposium (IRPS '16), IEEE, April 2016.

[93] K. Y. Lau, A. S. Vaughan, G. Chen, and I. L. Hosier, "Polyethylene nanodielectrics: the effect of nanosilica and its surface 
treatment on electrical breakdown strength," in Proceedings of the IEEE Conference on Electrical Insulation and Dielectric Phenomena (CEIDP '12), pp. 21-24, IEEE, October 2012.

[94] A. S. Vaughan, S. G. Swingler, and Y. Zhang, "Polyethylene nanodielectrics: The influence of nanoclays on structure formation and dielectric breakdown," IEEJ Transactions on Fundamentals and Materials, vol. 126, no. 11, pp. 1057-1063, 2006.

[95] J. K. Nelson and J. C. Fothergill, "Internal charge behaviour of nanocomposites," Nanotechnology, vol. 15, no. 5, pp. 586-595, 2004.

[96] R. J. Crawford, Plastics Engineering, Butterworth-Heinemann, 1998.

[97] M. Kollosche and G. Kofod, "Electrical failure in blends of chemically identical, soft thermoplastic elastomers with different elastic stiffness," Applied Physics Letters, vol. 96, no. 7, Article ID 071904, 2010.

[98] J. P. Jones, J. P. Llewellyn, and T. J. Lewis, “The contribution of field-induced morphological change to the electrical aging and breakdown of polyethylene," IEEE Electrical Insulation and Dielectric Phenomena, vol. 12, no. 5, pp. 951-966, 2005.

[99] D. Ma, T. A. Hugener, R. W. Siegel et al., "Influence of nanoparticle surface modification on the electrical behaviour of polyethylene nanocomposites," Nanotechnology, vol. 16, no. 6, pp. 724-731, 2005.

[100] X. Y. Huang, Z. S. Ma, Y. Q. Wang, P. K. Jiang, Y. Yin, and $\mathrm{Z}$. Li, "Polyethylene/aluminum nanocomposites: improvement of dielectric strength by nanoparticle surface modification," Journal of Applied Polymer Science, vol. 113, no. 6, pp. 3577-3584, 2009.

[101] Y. Yin, X. Dong, Z. Li, and X. Li, "The effect of electrically prestressing on DC breakdown strength in the nanocomposite of low-density polyethylene/nano-SiOx," in Proceedings of the International Conference on Solid Dielectrics (ICSD '07), pp. 372-376, IEEE, July 2007.

[102] M. Nagao, T. Kimura, Y. Mizuno, M. Kosaki, and M. Ieda, "Detection of Joule heating before dielectric breakdown in polyethylene films," IEEE Transactions on Dielectrics and Electrical Insulation, vol. 25, no. 4, pp. 715-722, 1990. 


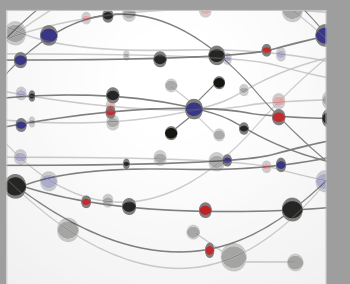

The Scientific World Journal
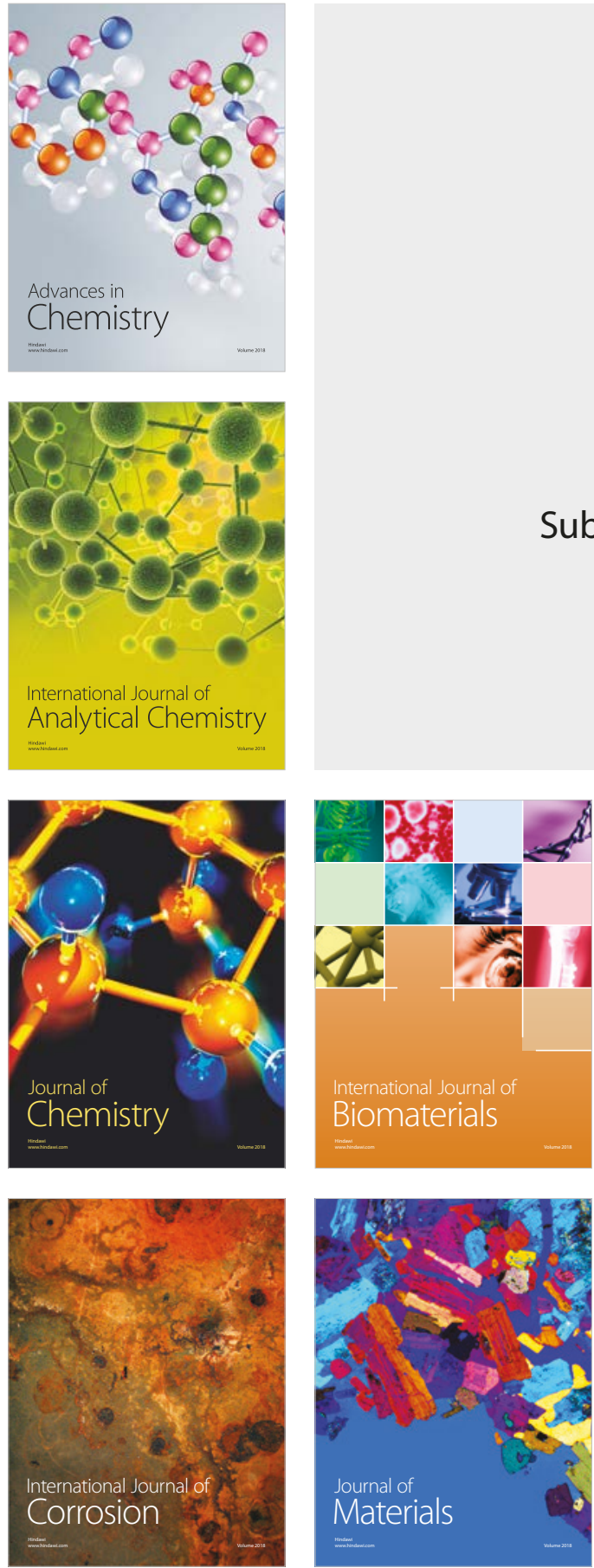

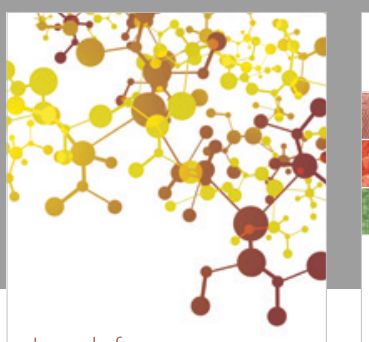

Journal of

Applied Chemistry
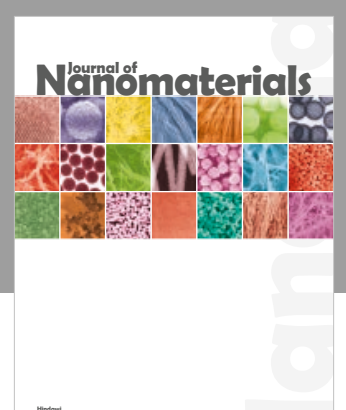

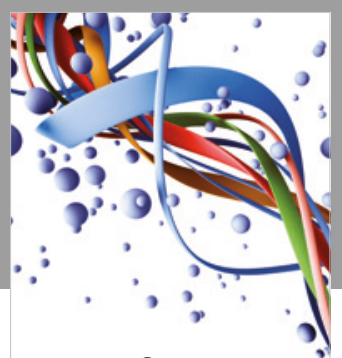

Scientifica

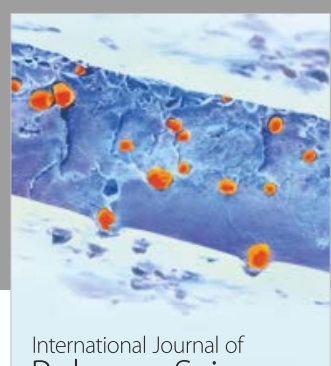

Polymer Science

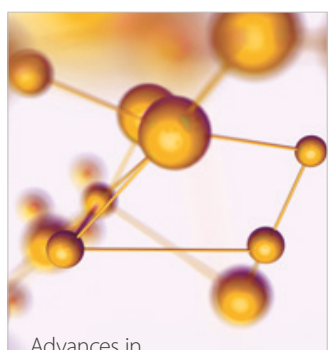

Physical Chemistry
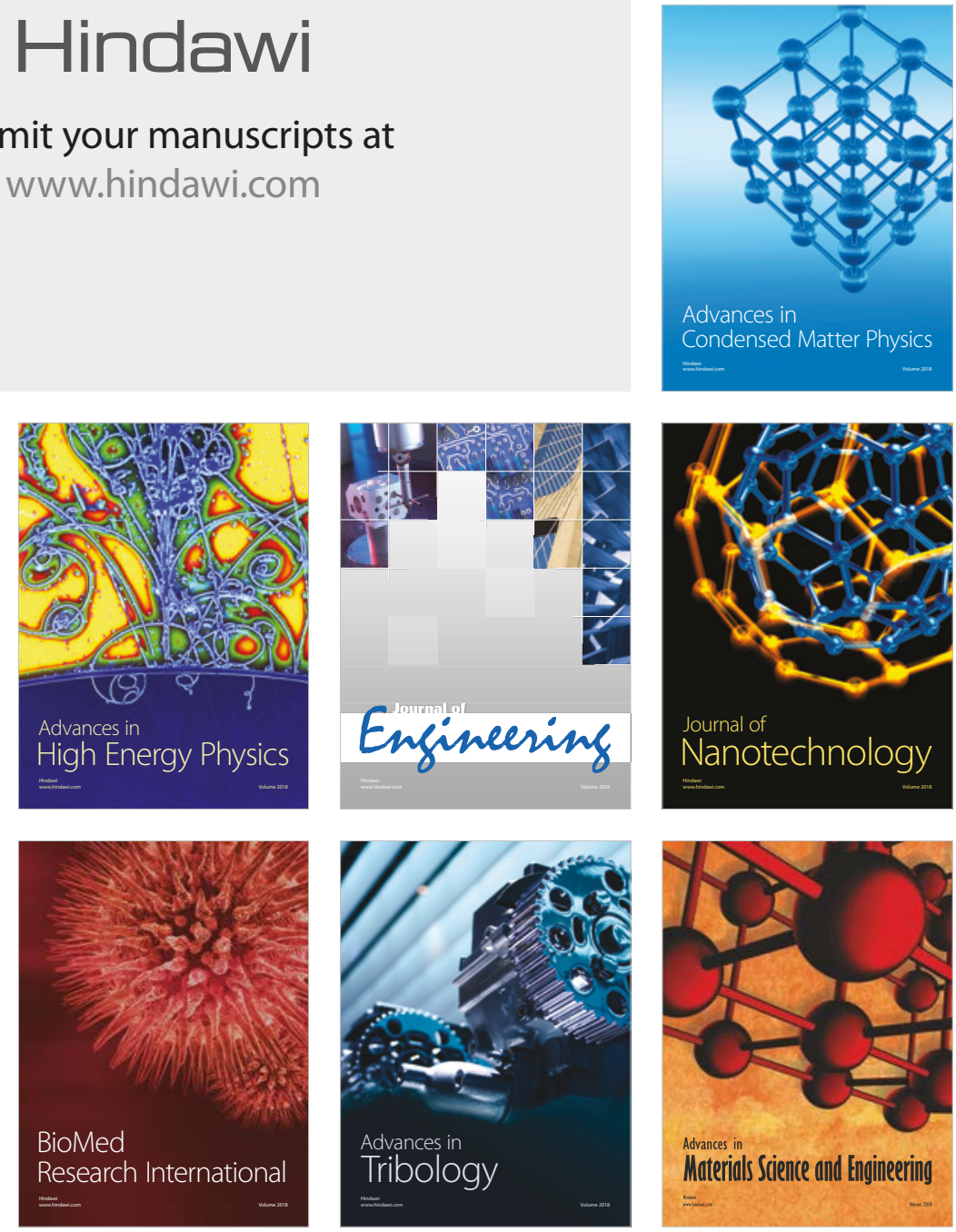